\title{
Synthesis of Fingolimod Employing Regioselective Aziridine Ring-Opening Reaction as a Key Step
}

\section{Supporting Information}

Jan Doubský, * Stanislav Rádl, Josef Cinibulk, Robert Klvañał

API Synthesis Development, Zentiva, k.s., U Kabelovny 130, 102 37, Prague 10, Czech

Republic; †Present Address: Teva Czech Industries s.r.o., Ostravská 305/29, Opava - Komárov, 74770, Czech Republic

*Email: jan.doubsky@zentiva.com 


\section{Table of Contents:}

1. Stability of the mesylate $\mathbf{1 3}$.

SI-3

2. Isolation, identification, and structural elucidation of the impurity 22.

SI-5

2.1. Isolation of the impurity 22 .

SI-5

2.2. Structural elucidation of the impurity 22 .

SI-7

2.3. Comparison of the isolated impurity 22 with the synthetic sample.

SI-12

3. Selected analytical data of a fingolimod hydrochloride (1) $500 \mathrm{~g}$ validation batch

SI-13

4. NMR spectra of the key compounds.

SI-16 


\section{Stability of the mesylate 13 .}

NMR spectra of different samples of the mesylate 13, varying in storage conditions and/or initial purity.

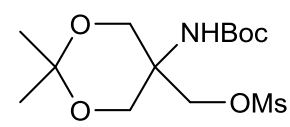

13

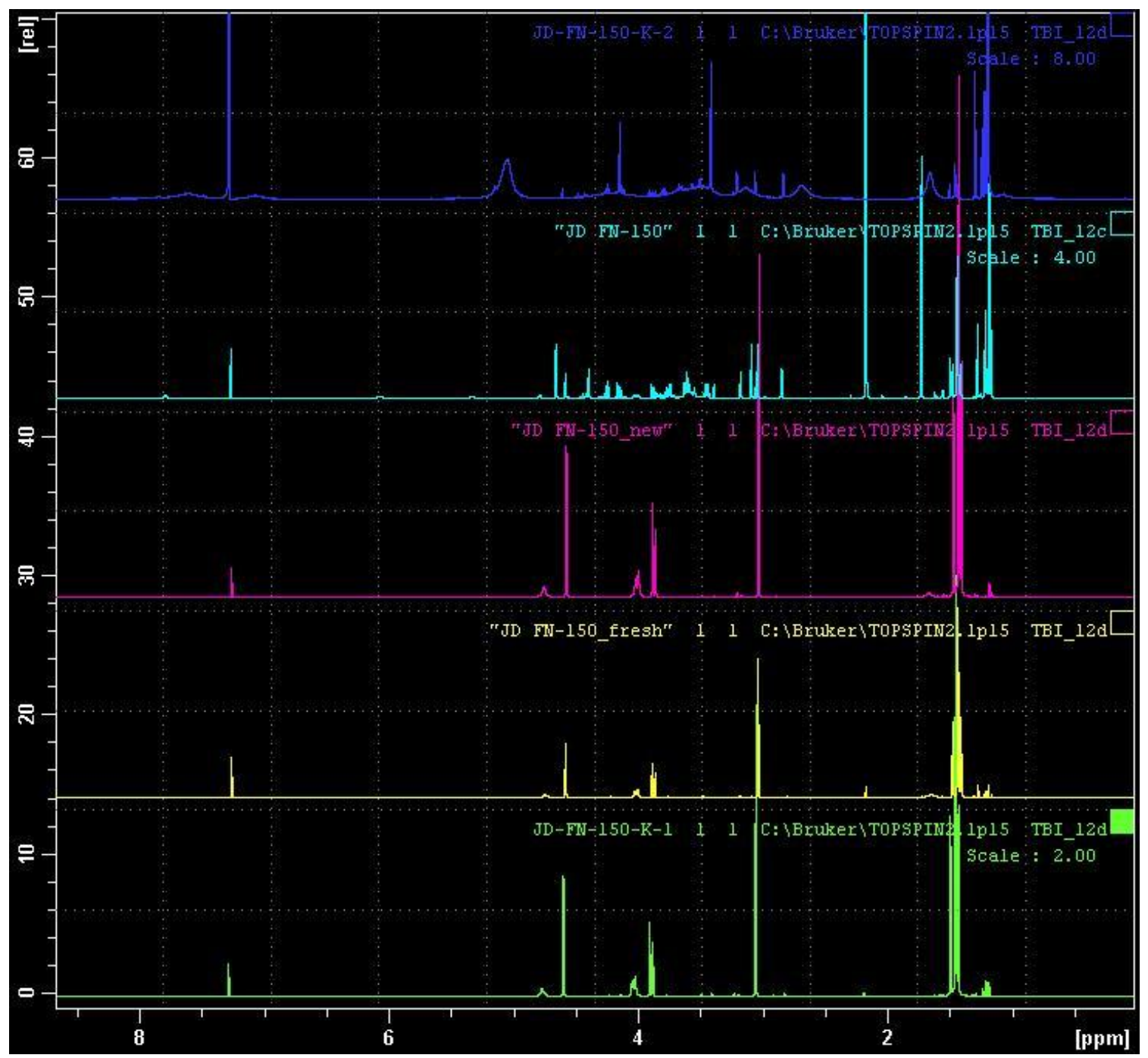

Figure S1. ${ }^{1} \mathrm{H}-\mathrm{NMR}, \mathrm{CDCl}_{3}, 500 \mathrm{MHz}$. Green - 1 month old sample (stored in the dark at r.t.). Yellow - freshly synthesized sample. Magenta - recrystallized material (stored for 2 weeks under day-light at r.t.). Cyan -1 month old sample - initial purity $>95 \%$ (stored under day-light at r.t.). Blue -1 month old sample - initial purity $>80 \%$ (stored under day-light at r.t.). 


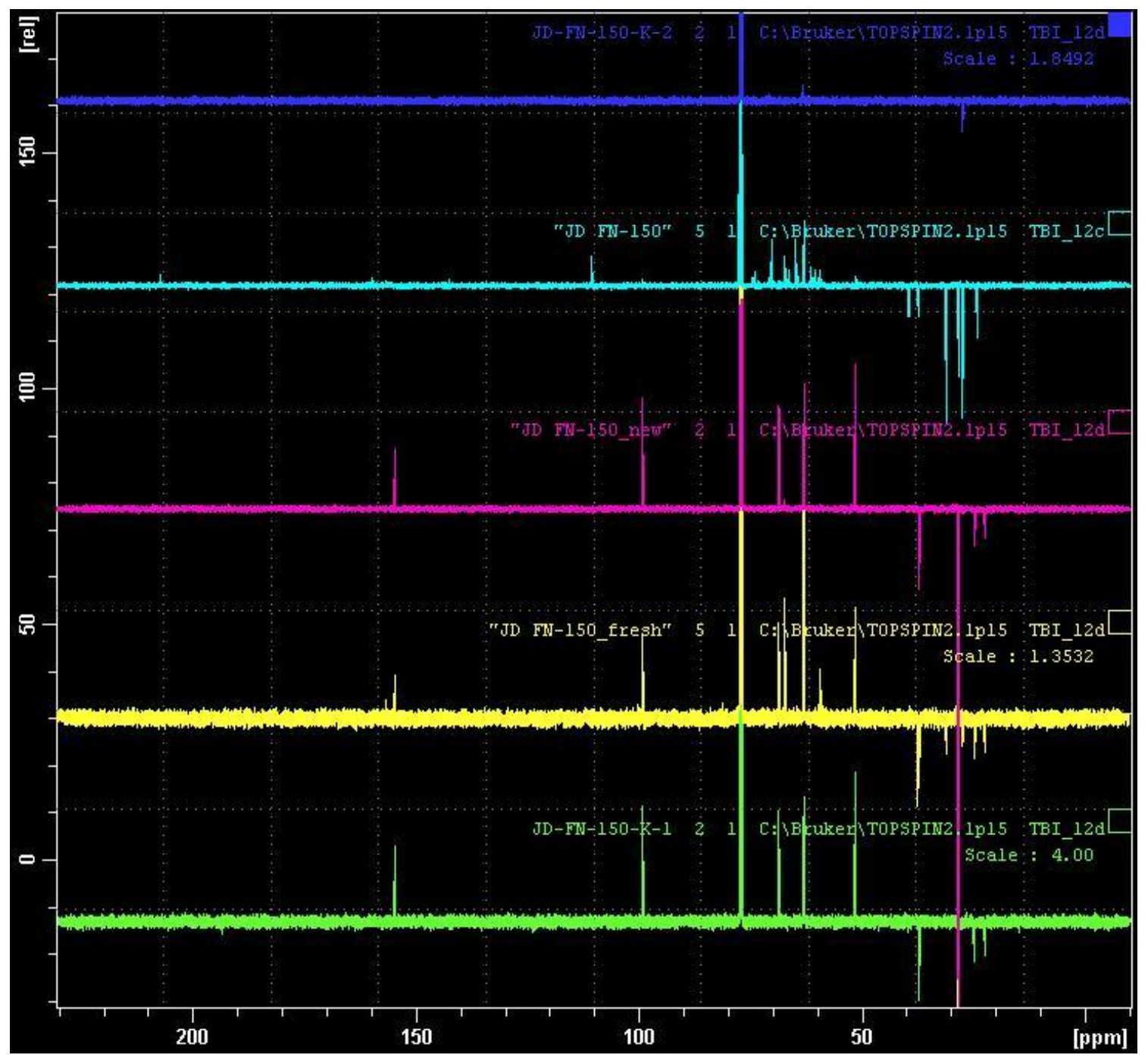

Figure S2. ${ }^{13} \mathrm{C}$-NMR (APT), $\mathrm{CDCl}_{3}, 125 \mathrm{MHz}$. Green - 1 month old sample (stored in the dark at r.t.). Yellow - freshly synthesized sample. Magenta - recrystallized material (stored for 2 weeks under day-light at r.t.). Cyan - 1 month old sample - initial purity $>95 \%$ (stored under day-light at r.t.). Blue -1 month old sample - initial purity $>80 \%$ (stored under day-light at r.t.). 


\section{Isolation, identification, and structural elucidation of the impurity 22.}

\subsection{Isolation of the impurity 22 .}

A $50 \mathrm{~g}$ sample of fingolimod hydrochloride (1) containing about $0.4 \%$ of the "unknown impurity" (identified later as 22) was dissolved in a mixture of $35 \mathrm{~mL}$ of $\mathrm{H}_{2} \mathrm{O}, 15 \mathrm{~mL}$ of acetonitrile, and $1 \mathrm{~mL}$ of $85 \% \mathrm{H}_{3} \mathrm{PO}_{4}$ (aq.) at $60{ }^{\circ} \mathrm{C}$ (the solvent mixture was identical with intended mobile phase for the subsequent LC-separation). The clear solution was left to cool down to the room temperature. The crystalline material separated out of this solution upon an above overnight cooling, was found to be almost pure fingolimod hydrochloride (1), while the most of the "unknown impurity" remained in mother liquor.

The above mother liquor was subjected to LC-separation using a Büchi Sepacore ${ }^{\circledR}$ Chromatography Systems equipped with an in-house made column (height $12 \mathrm{~cm}$, diameter 4 $\mathrm{cm}$ ) filled with $\mathrm{C}-18$ phase, and using a mixture of $35 \mathrm{~mL}$ of $\mathrm{H}_{2} \mathrm{O}, 15 \mathrm{~mL}$ of acetonitrile, and 1 $\mathrm{mL}$ of $85 \% \mathrm{H}_{3} \mathrm{PO}_{4}$ (aq.) as a mobile phase. Fractions containing the desired impurity were collected, concentrated under a reduced pressure and subjected to the same purification procedure repeatedly. After three repetitions, $65 \mathrm{mg}$ of a sample containing $68 \%$ of the "unknown impurity" was obtained (Figure S3). Afterwards, this material was purified using a preparative HPLC (C-18 column, diameter $4.6 \mathrm{~mm}$, length $150 \mathrm{~mm}$; mobile phase: 5-95\% $\mathrm{MeCN}$ in $\mathrm{H}_{2} \mathrm{O}$, containing $0.1 \mathrm{wt} \%$ of formic acid) affording thus $26 \mathrm{mg}$ of the "unknown impurity" (HPLC purity: >97 \%) which was used to elucidate its structure unambiguously. 


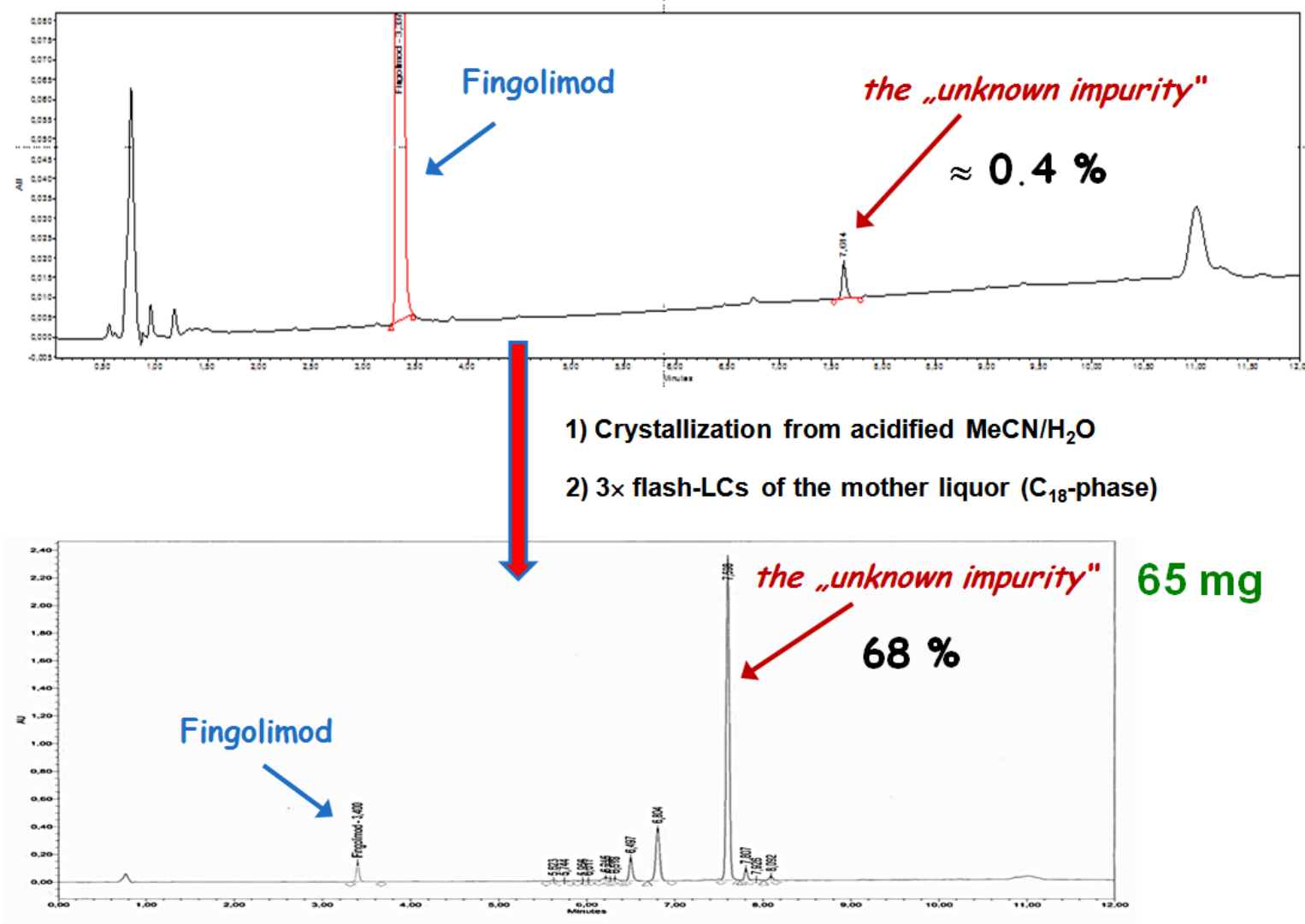

Figure S3. The "unknown impurity" isolation. 


\subsection{Structural elucidation of the impurity 22 .}

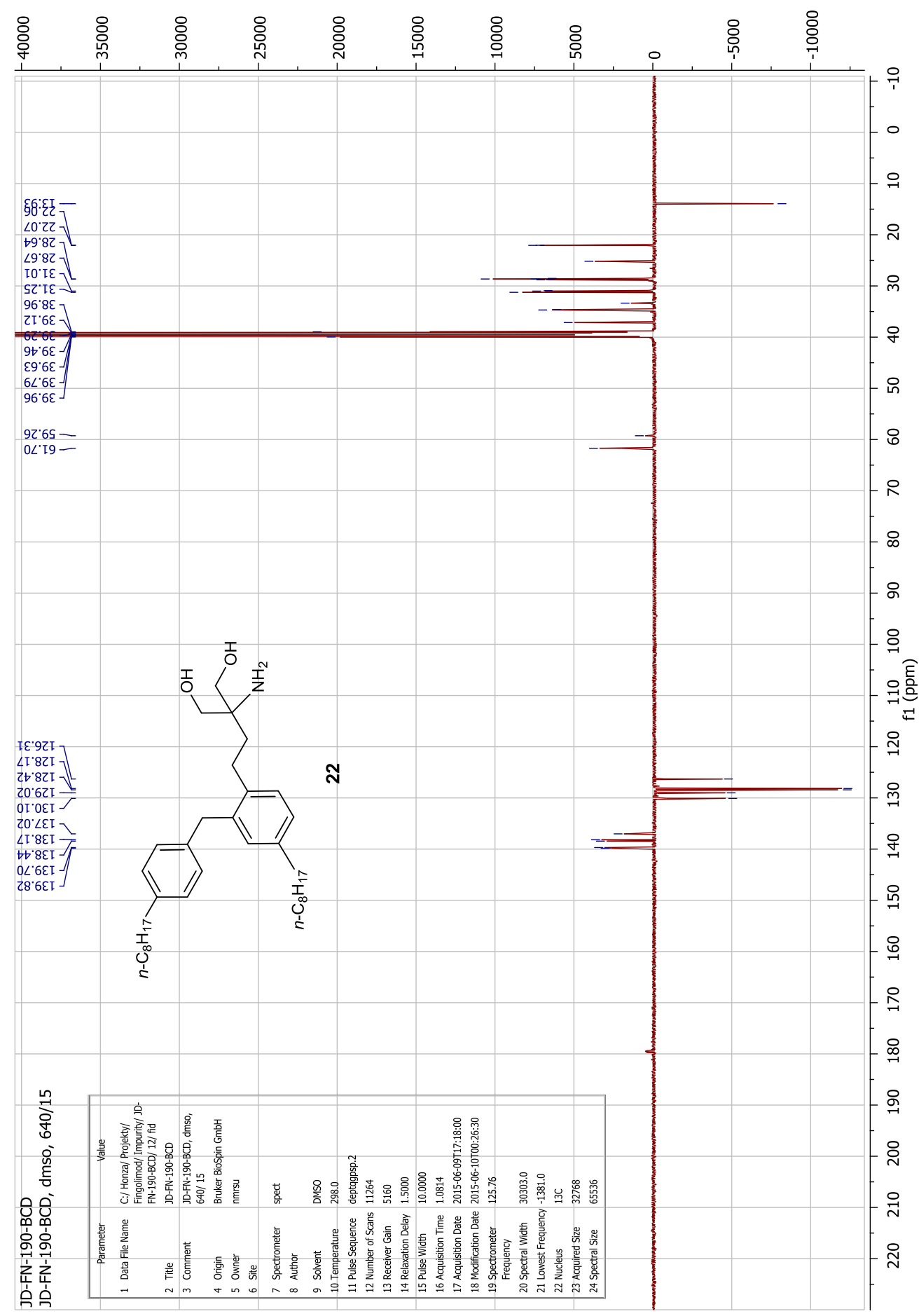

Figure S4. ${ }^{13} \mathrm{C}-\mathrm{NMR}$ (d6-DMSO, $125 \mathrm{MHz}$ ) spectrum of the isolated impurity 22. 


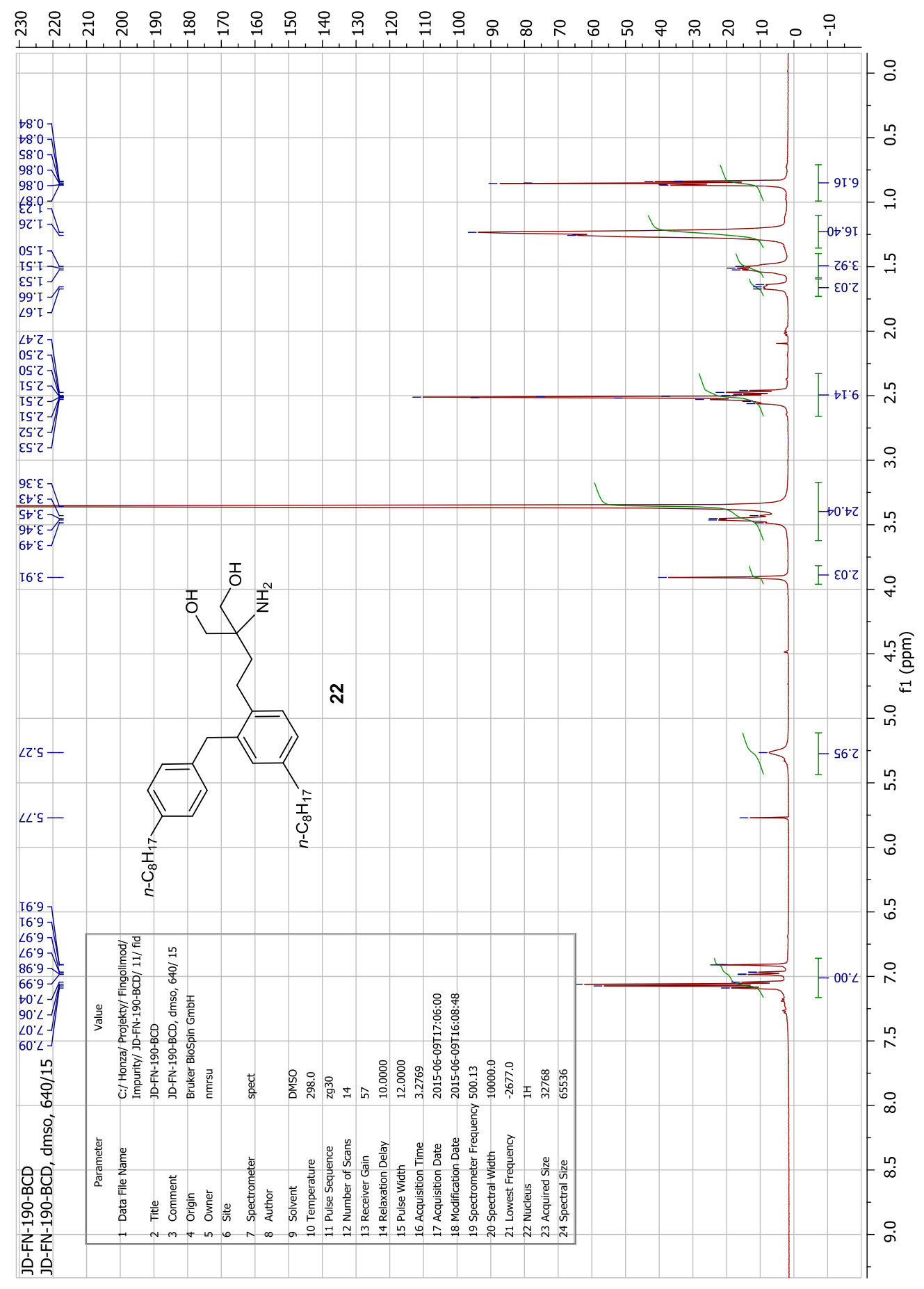

Figure S5. ${ }^{1} \mathrm{H}-\mathrm{NMR}($ d6-DMSO, $500 \mathrm{MHz})$ spectrum of the isolated impurity 22. 


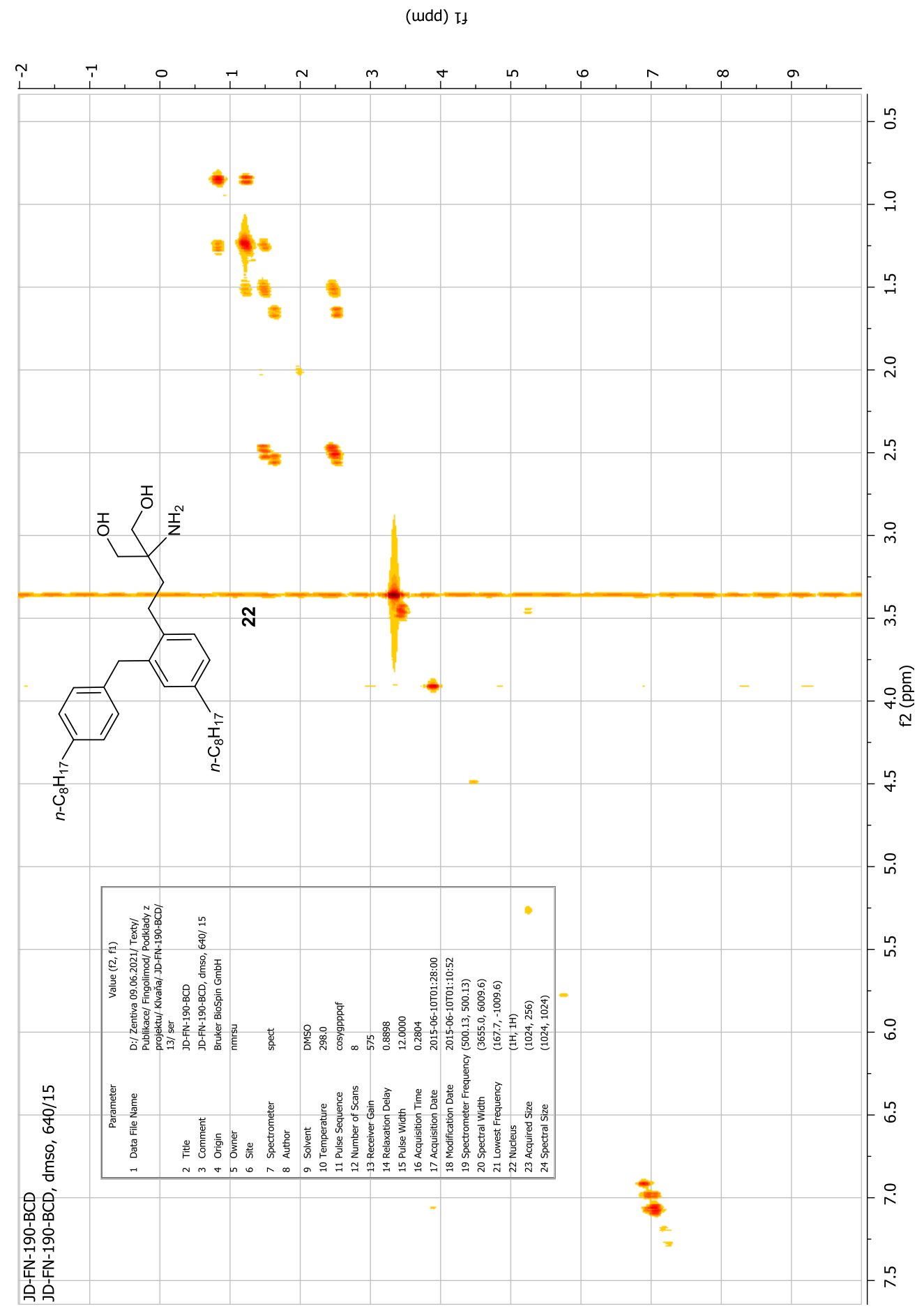

Figure S6. COSY-NMR (d6-DMSO, $500 \mathrm{MHz}$ ) spectrum of the isolated impurity 22. 


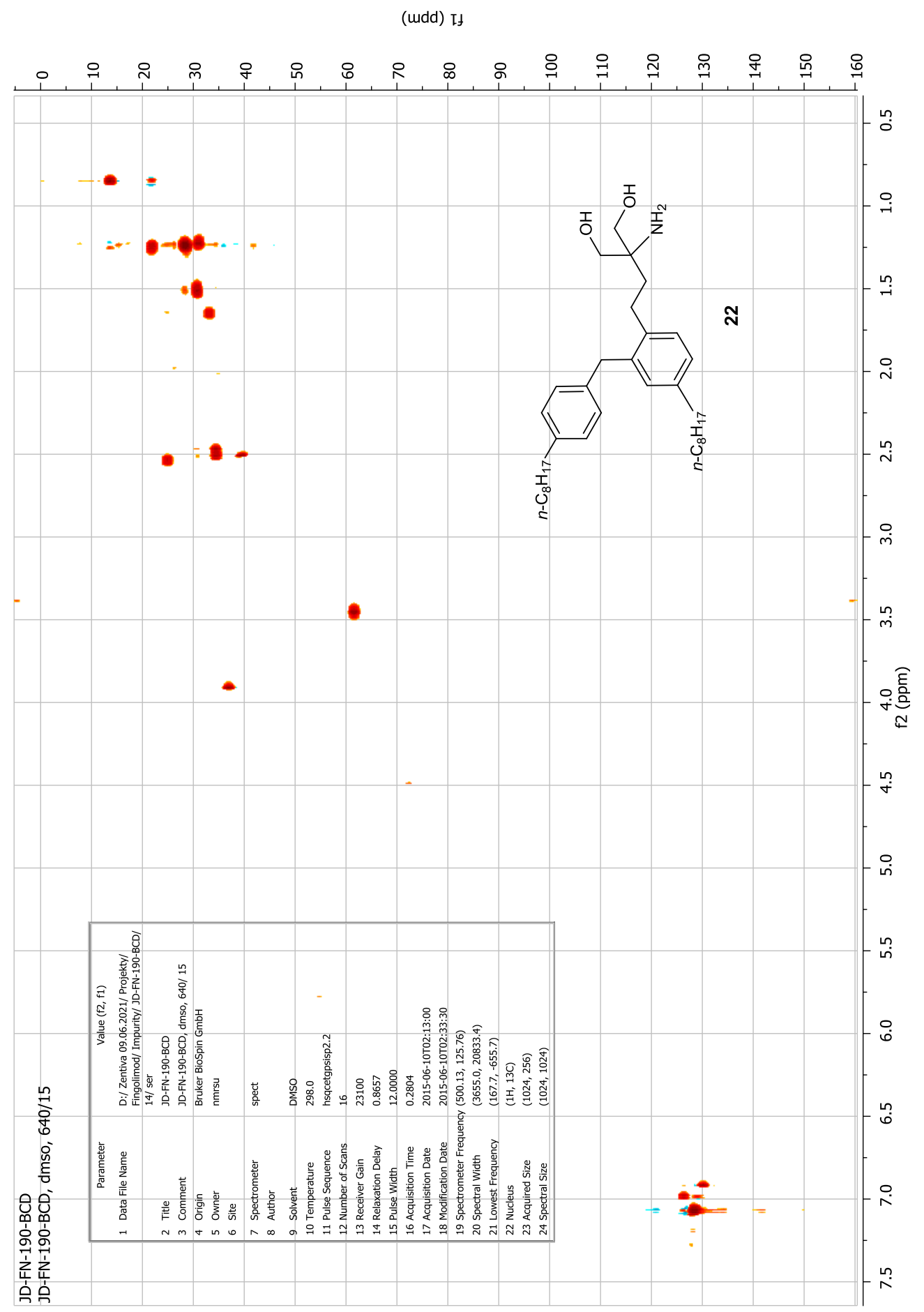

Figure S7. HSQC-NMR (d6-DMSO, 500 and $125 \mathrm{MHz}$ ) spectrum of the isolated impurity 22. 


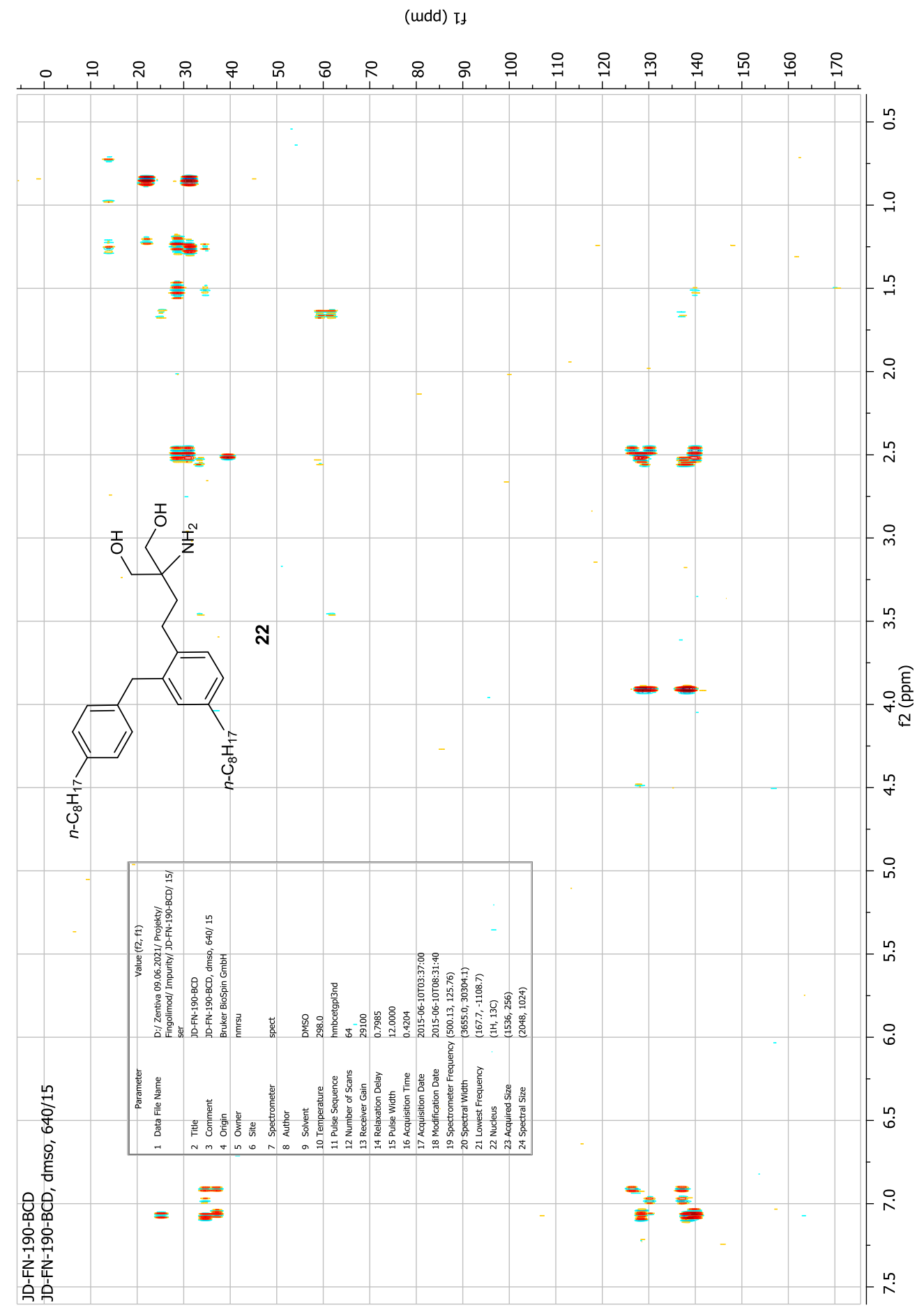

Figure S8. HMBC-NMR (d6-DMSO, 500 and $125 \mathrm{MHz}$ ) spectrum of the isolated impurity 22. 
2.3. Comparison of the isolated impurity 22 with the synthetic sample.

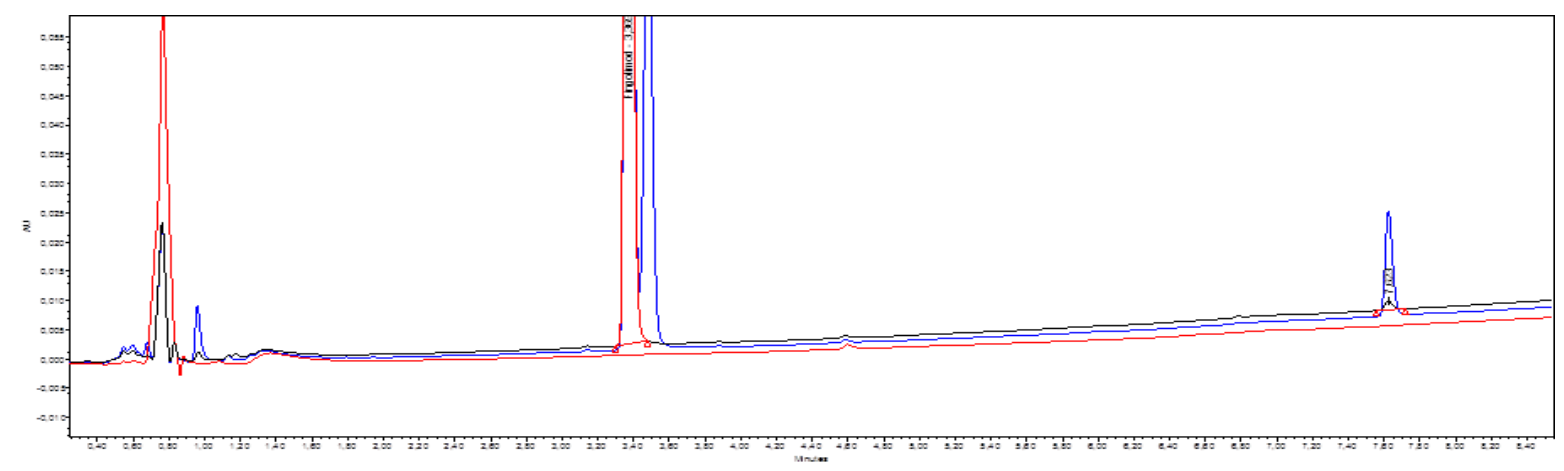

Figure S9. UPLC-chromatogram of the sample containing $0.4 \%$ of 22 (red) and the same one spiked with the synthetic 22 (blue).

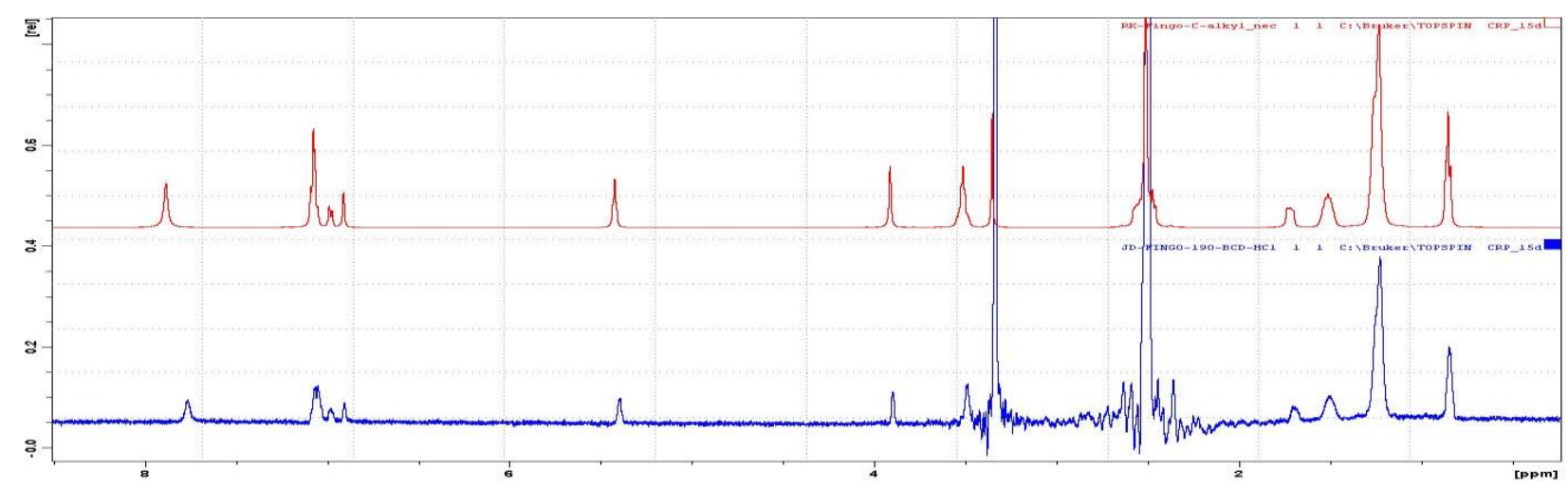

Figure S10. Comparison of ${ }^{1} \mathrm{H}-\mathrm{NMR}$ spectra (d6-DMSO, $500 \mathrm{MHz}$ ) of the synthetic sample of 22 (red) and the isolated one (blue). 


\section{Selected analytical data of a fingolimod hydrochloride (1) - 500g validation batch}

This batch (batch no. 4U001) was of $508 \mathrm{~g}$ of the final product 1 ("validation batch" means it was accomplished step by step from the beginning up to the final product). The whole synthetic process was carried out at Chinoin (Sanofi) plant in Budapest (Hungary).

\begin{tabular}{|c|c|c|}
\hline Test & Acceptance criteria & Results \\
\hline Appearance & $\begin{array}{c}\text { white, off-white to light gray } \\
\text { powder }\end{array}$ & off-white powder \\
\hline Polymorphism & Form 1 & Form 1 \\
\hline Related substances / Impu & & \\
\hline Compound 14 & $0.15 \%$ & $<0.05 \%$ \\
\hline Compound $\mathbf{2 1}$ & $0.15 \%$ & $<0.05 \%$ \\
\hline Compound 22 & $0.15 \%$ & $<0.05 \%$ \\
\hline Any unspecified imp. indiv. & $0.10 \%$ & $<0.05 \%$ \\
\hline Total impurities & $0.5 \%$ & $0.0 \%$ \\
\hline Water & $0.5 \%$ & $0.2 \%$ \\
\hline Sulfated ash & $0.1 \%$ & $0.1 \%$ \\
\hline
\end{tabular}




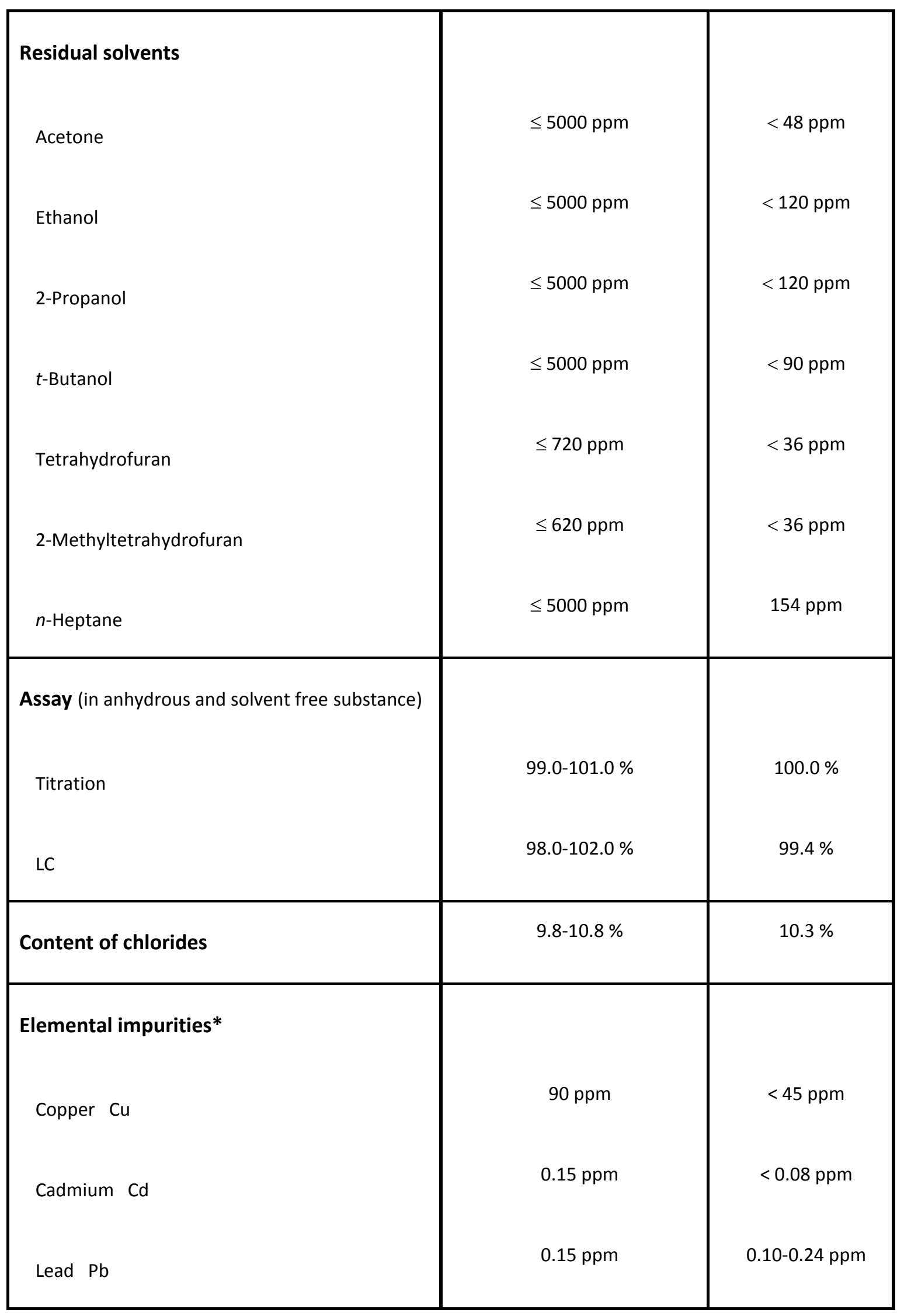




\begin{tabular}{|l|c|c|}
\hline Arsenic As & $0.45 \mathrm{ppm}$ & $<0.23 \mathrm{ppm}$ \\
Mercury Hg & $0.9 \mathrm{ppm}$ & $<0.5 \mathrm{ppm}$ \\
Nickel Ni & $6 \mathrm{ppm}$ & $3.9 \mathrm{ppm}$ \\
Lithium Li & $17 \mathrm{ppm}$ & $<8 \mathrm{ppm}$ \\
Tin Sn & & $<90 \mathrm{ppm}$ \\
Chromium Cr & $180 \mathrm{ppm}$ & $<165 \mathrm{ppm}$ \\
\hline
\end{tabular}

* Only selected metals presented. 


\section{NMR spectra of the key compounds.}

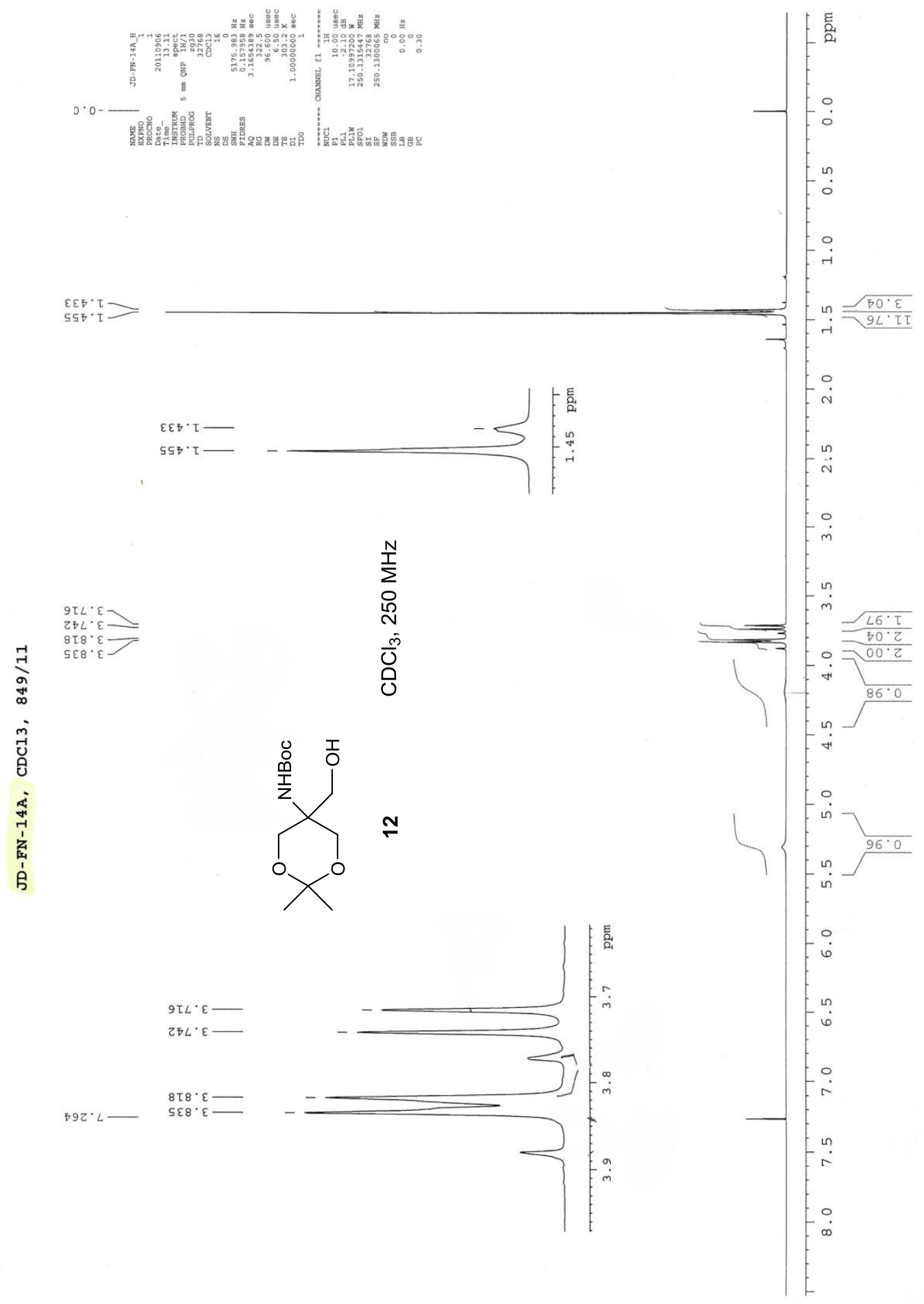




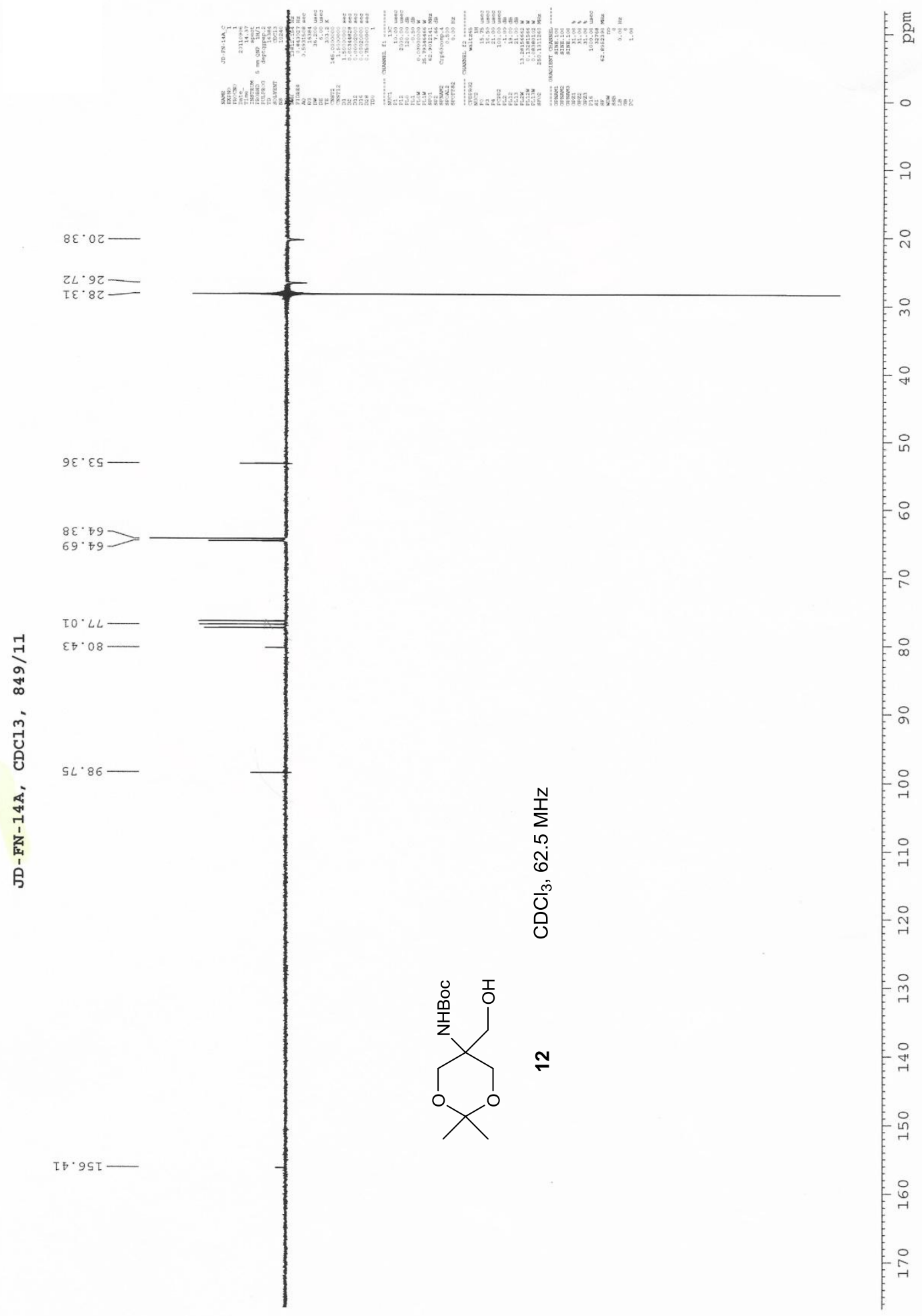




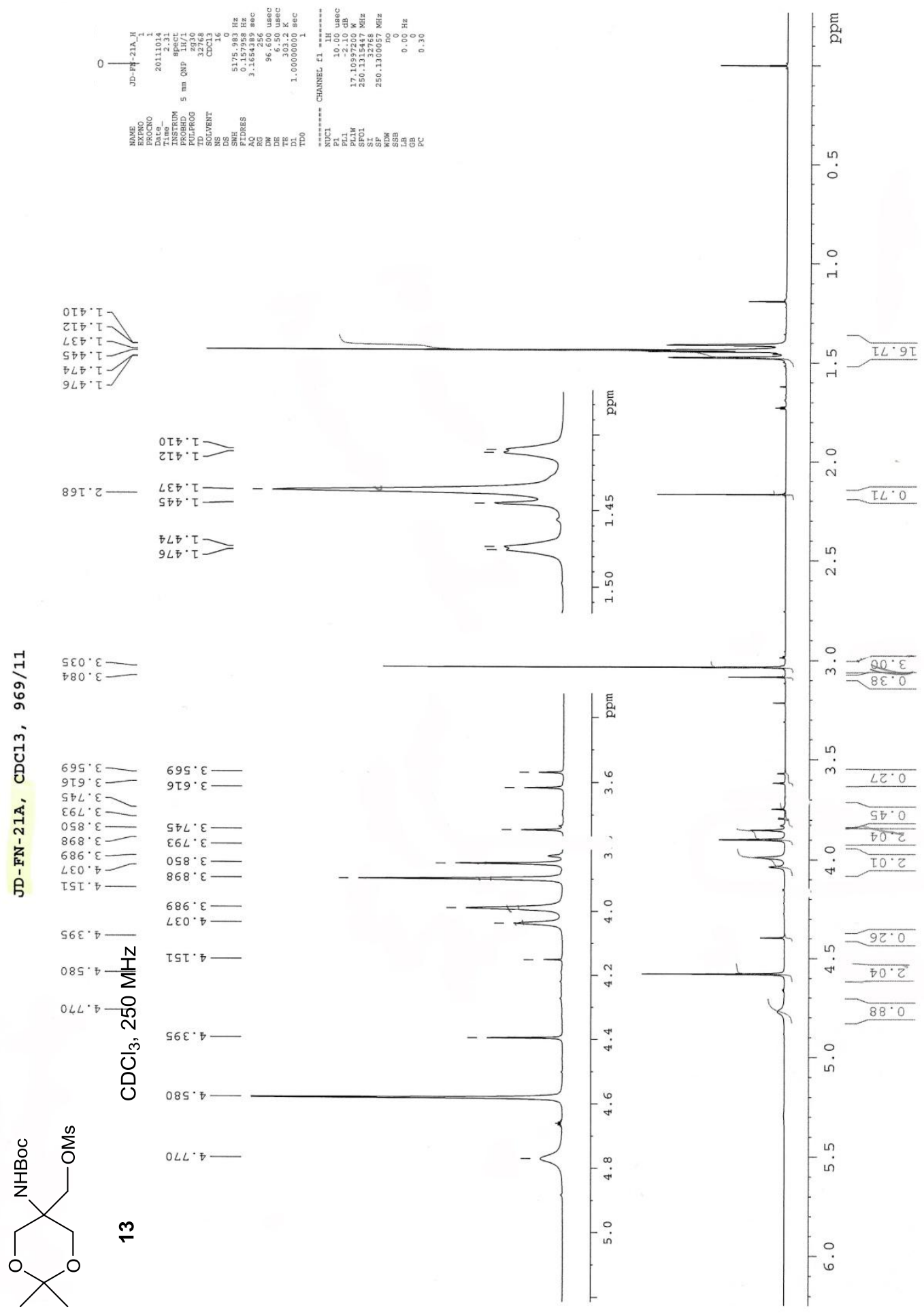




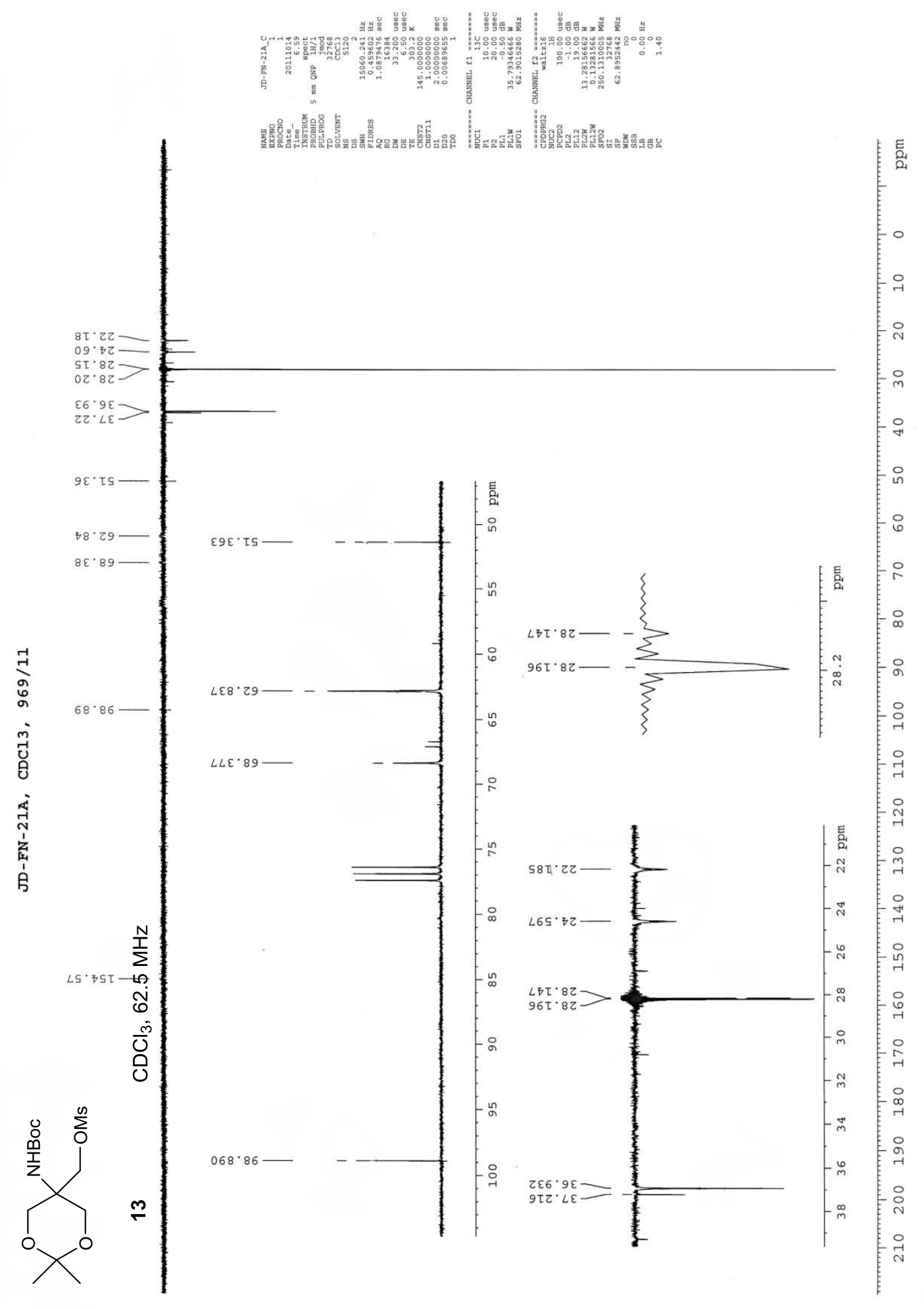




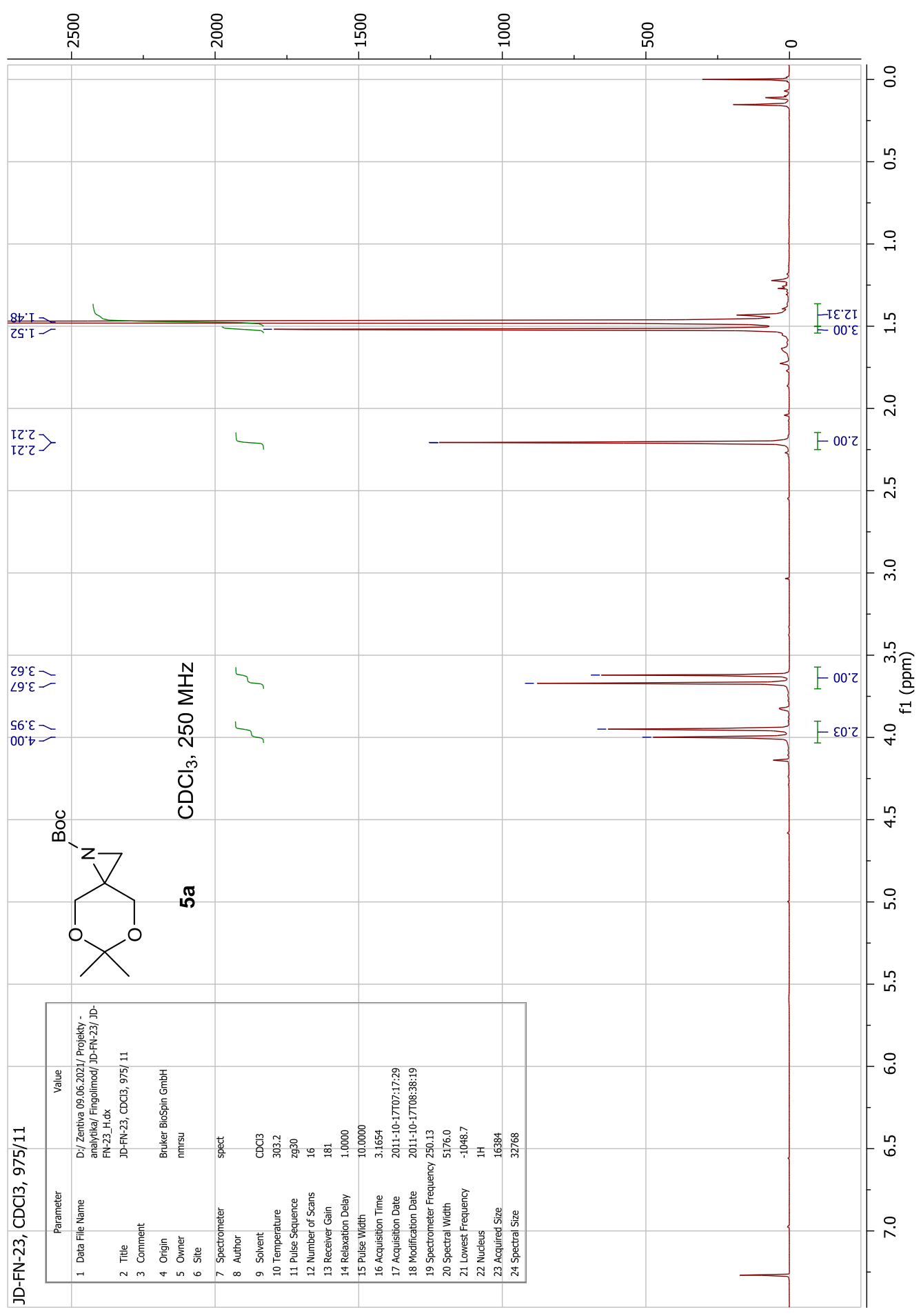




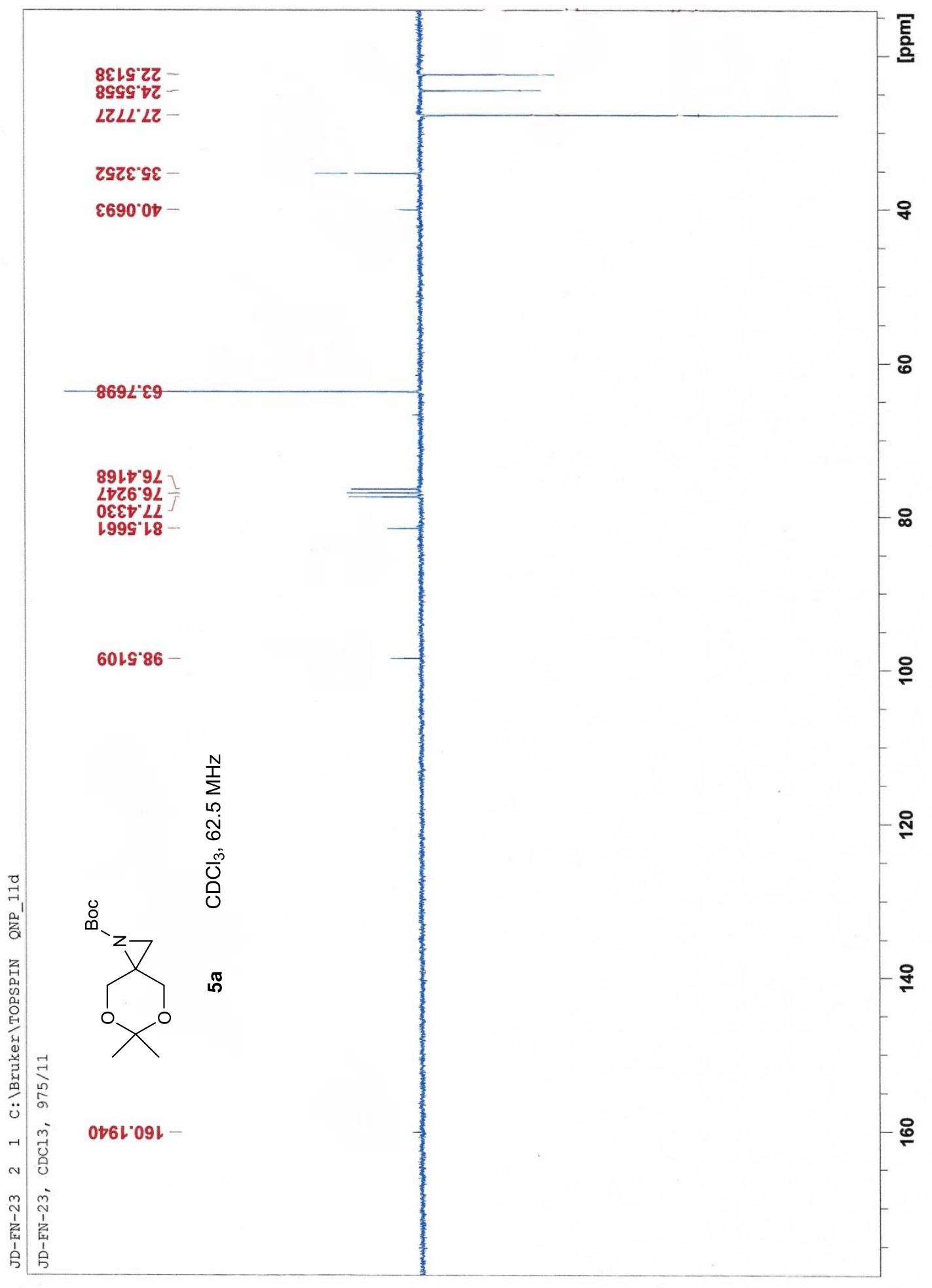




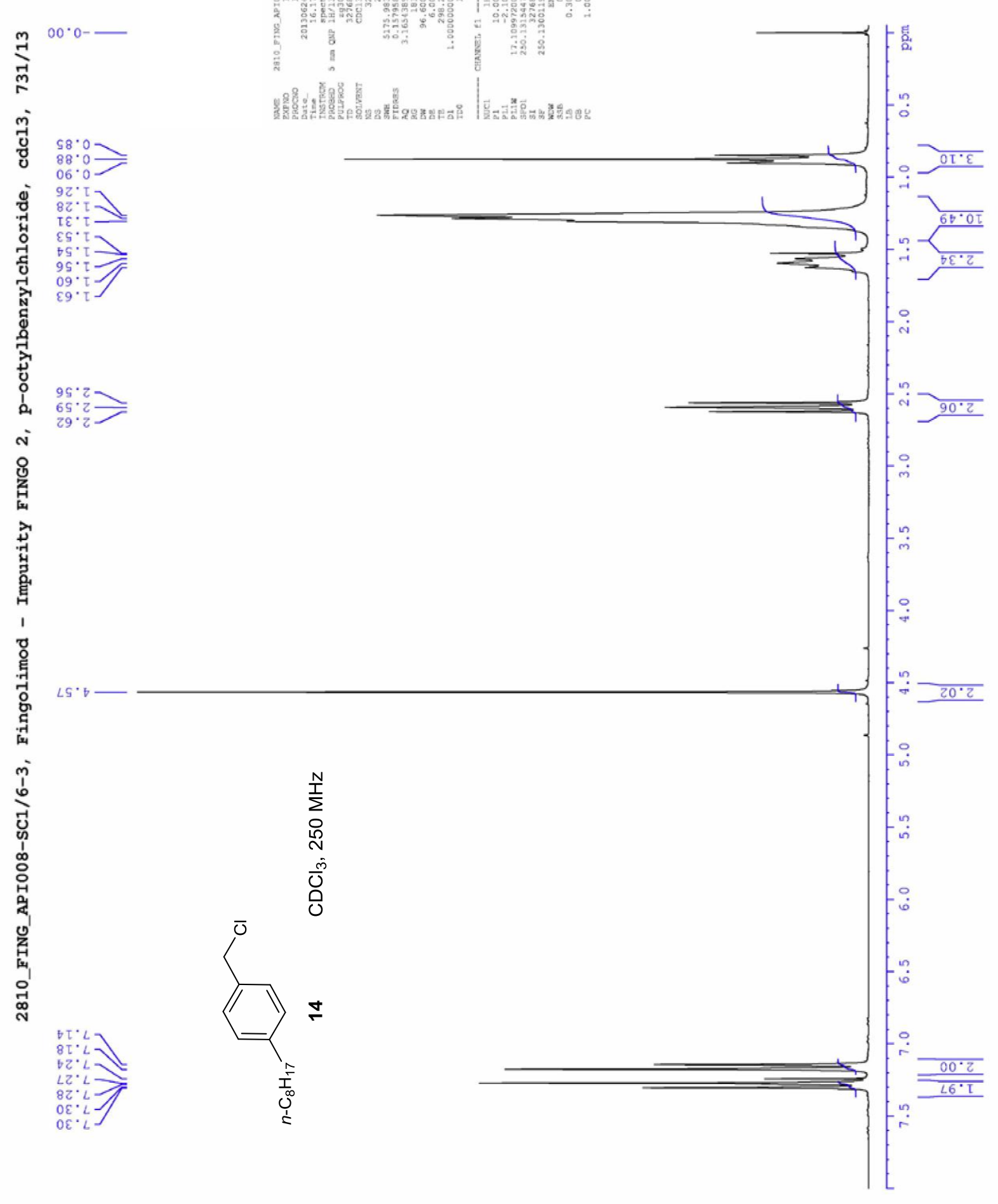




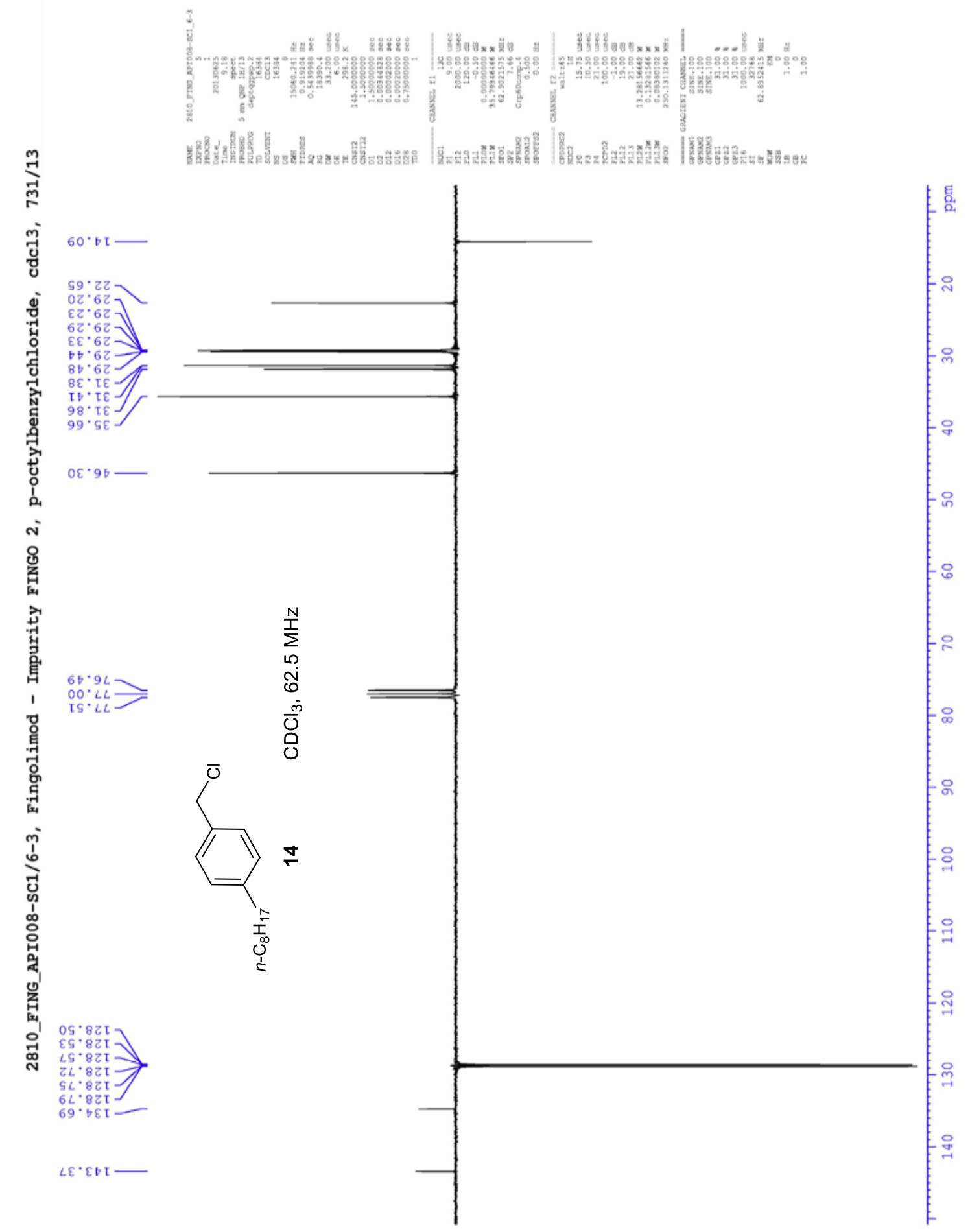




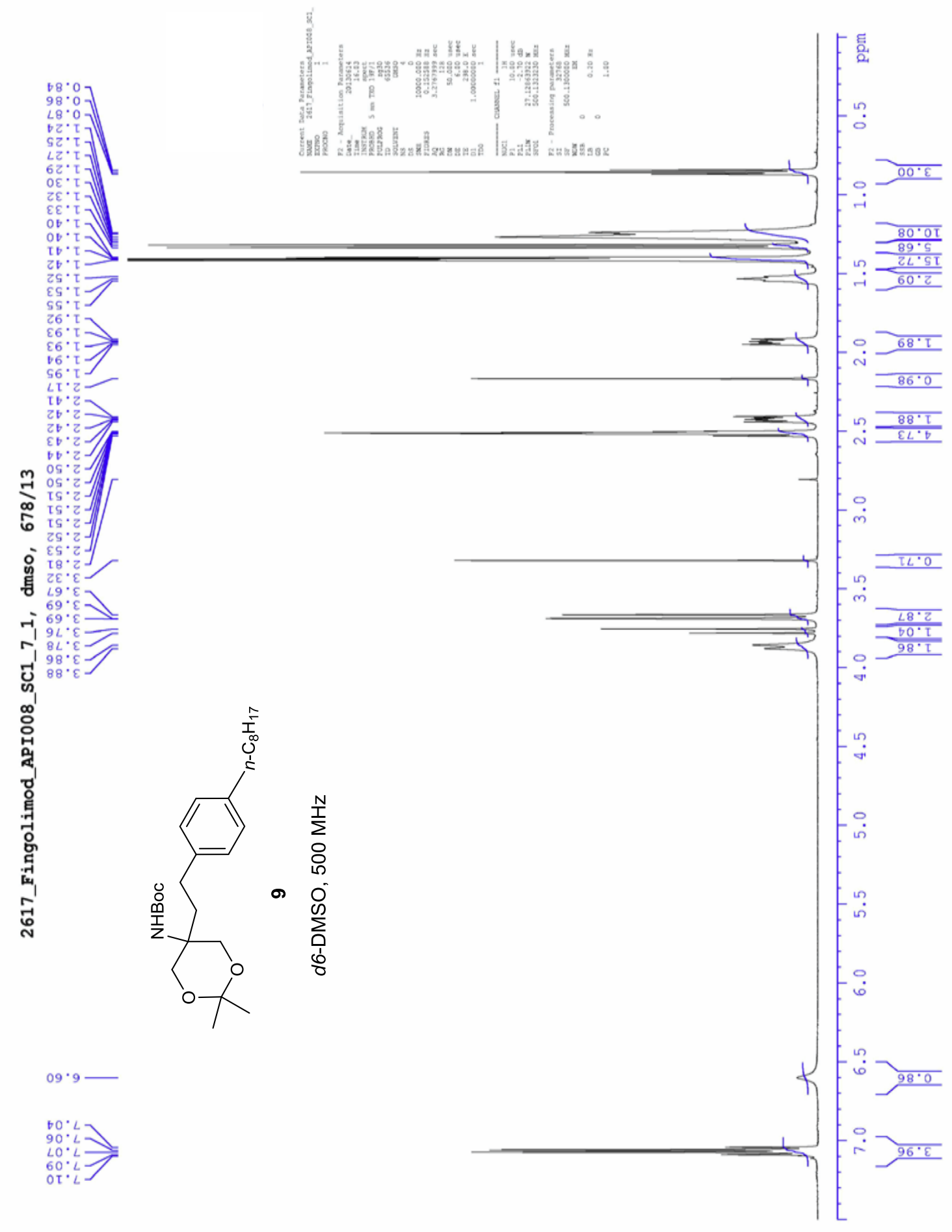




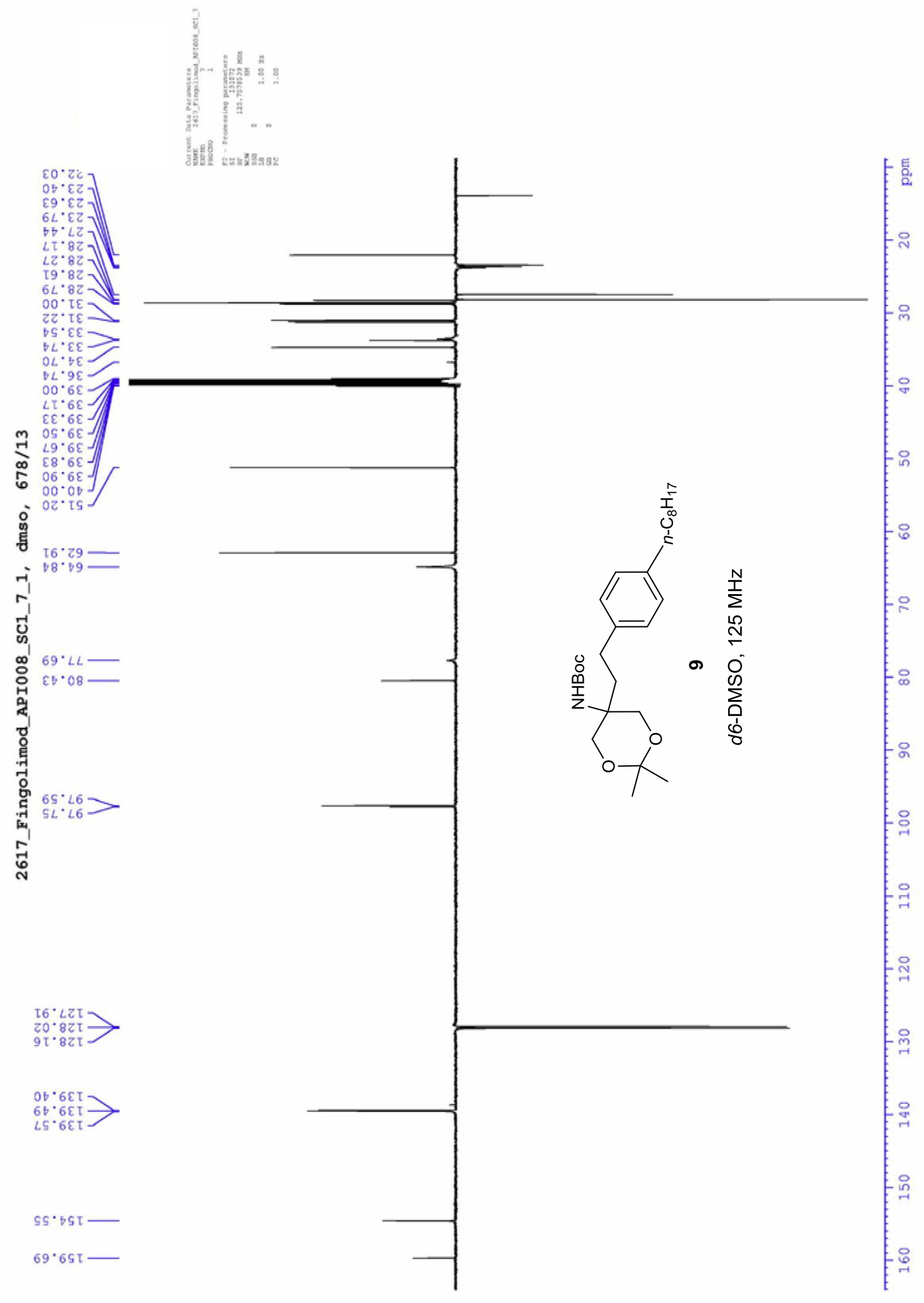




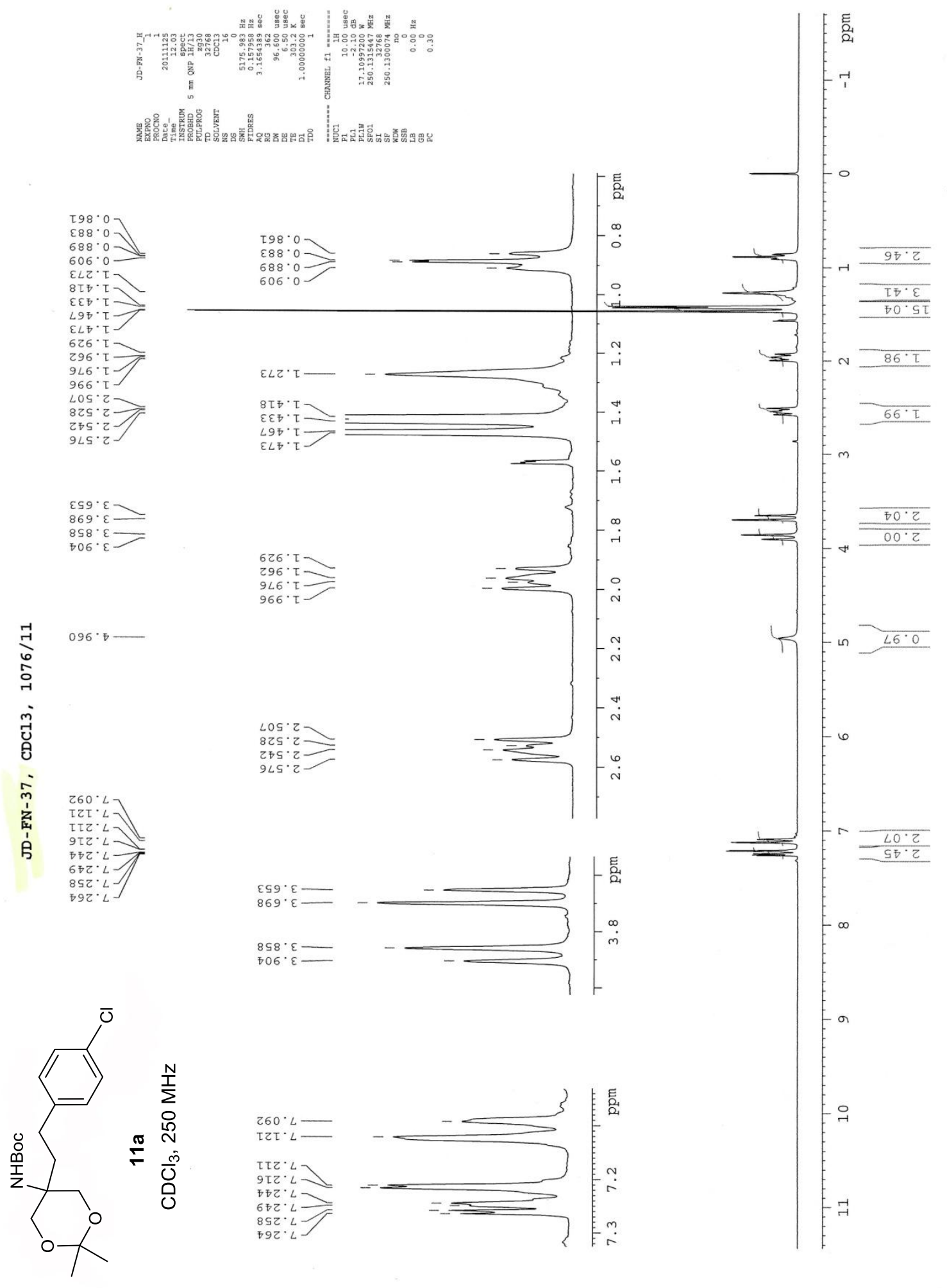




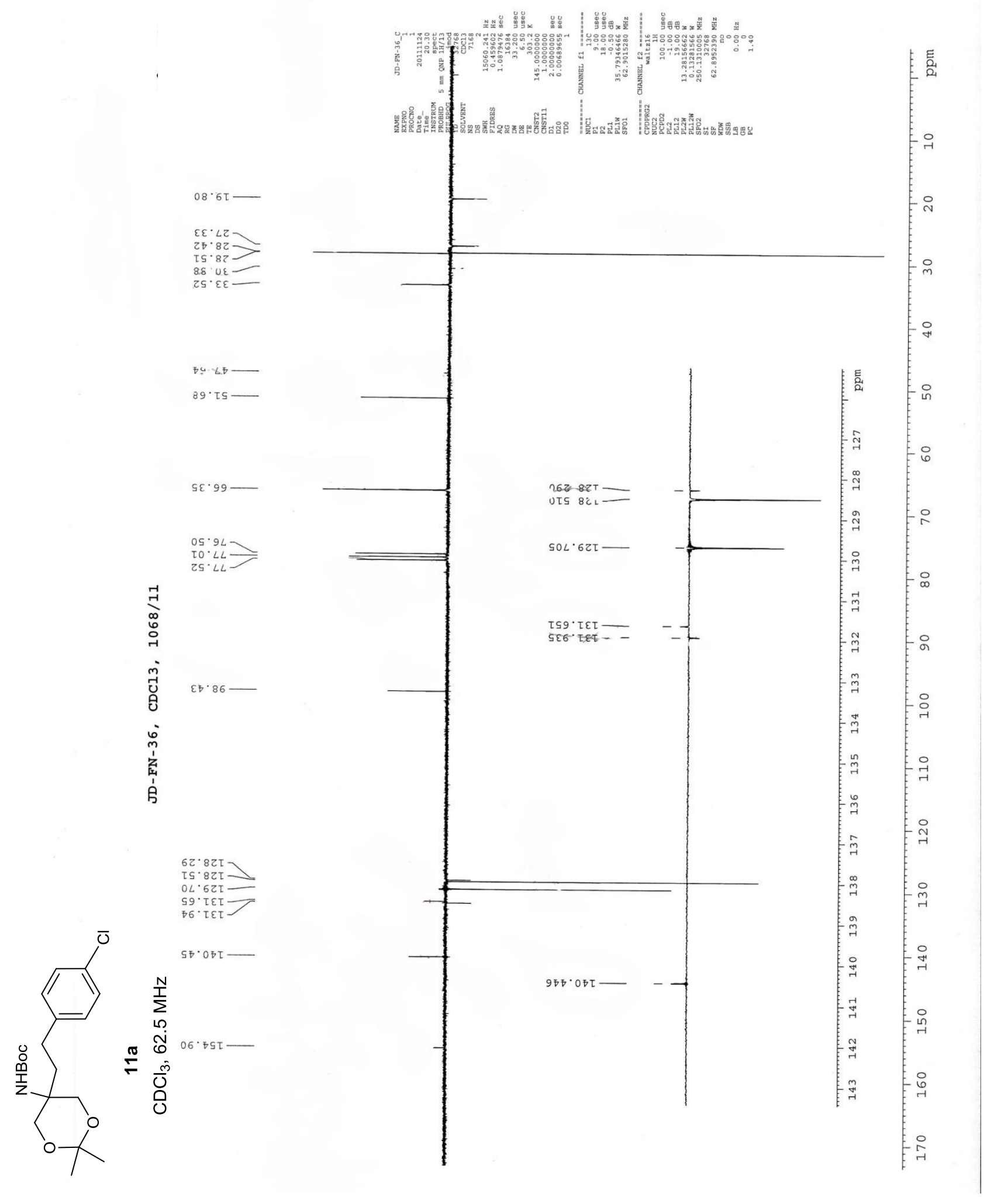




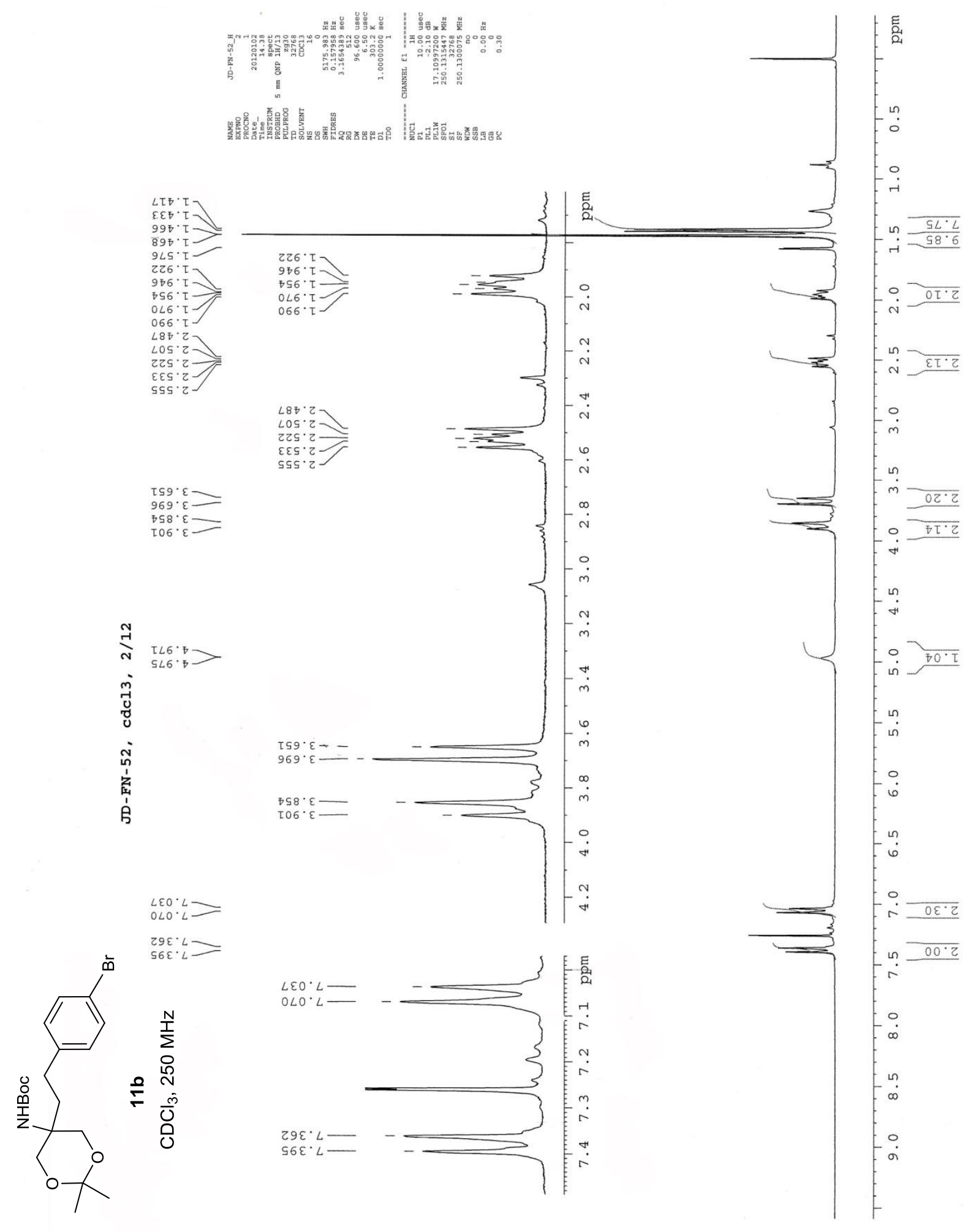




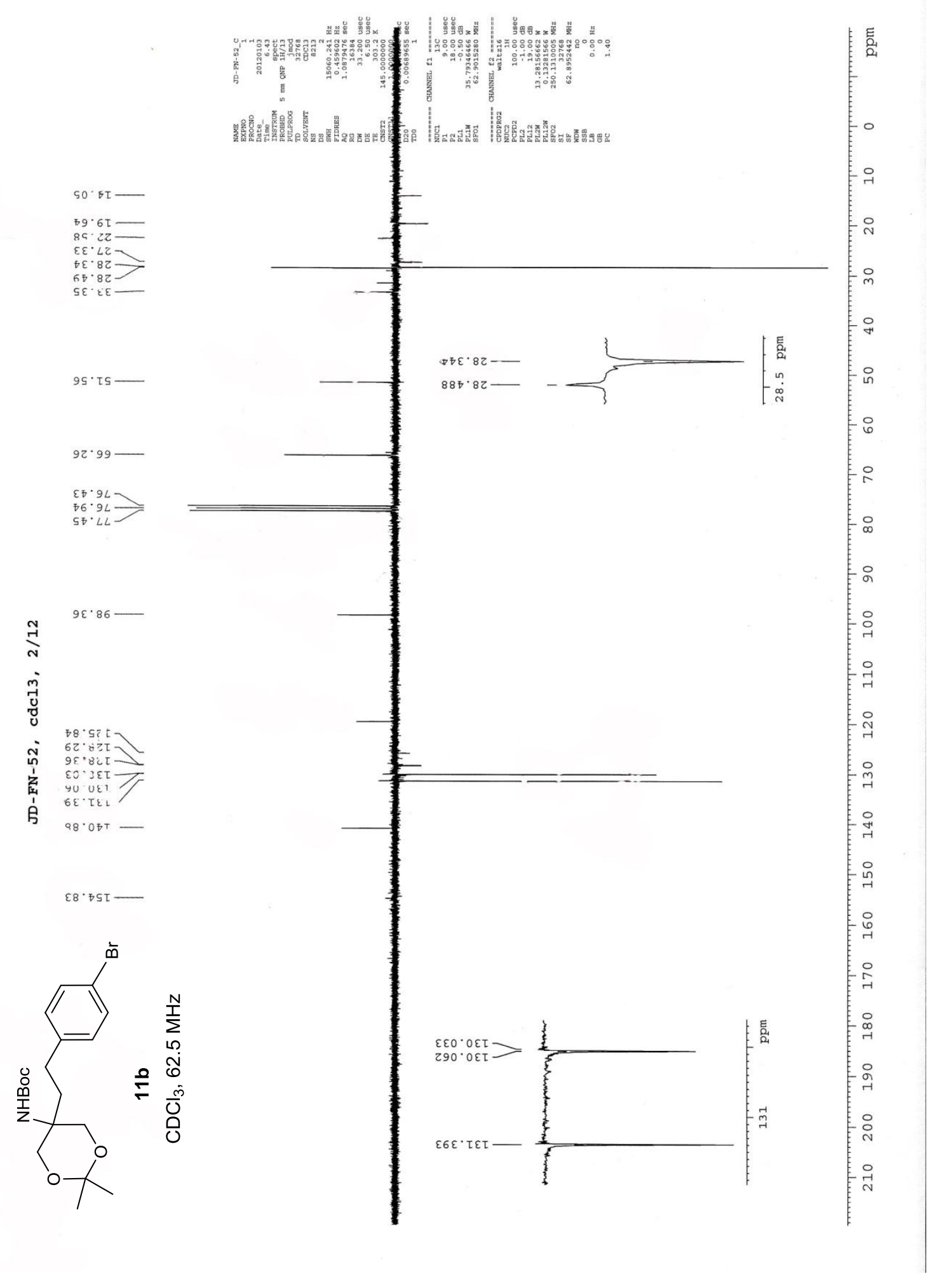




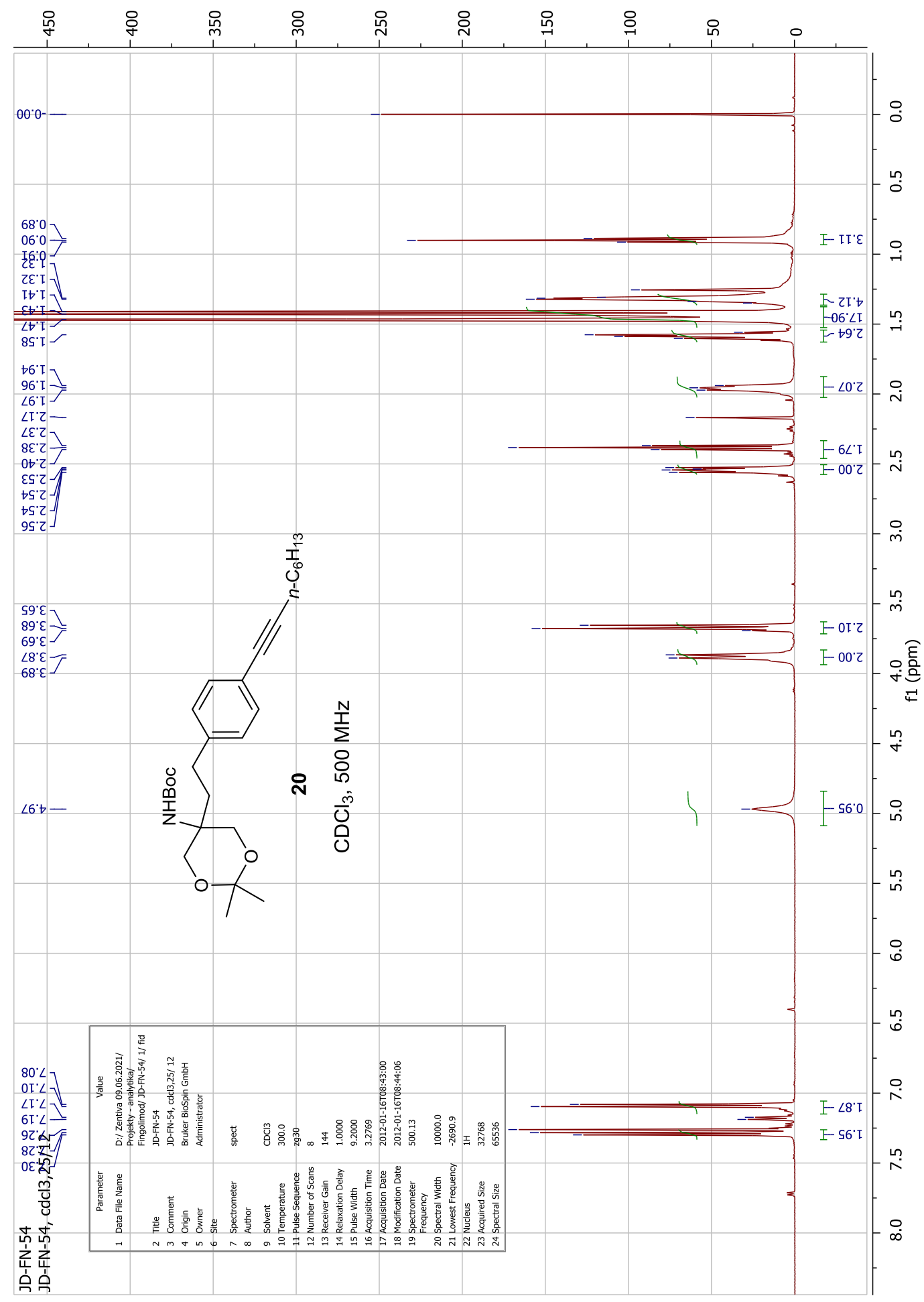




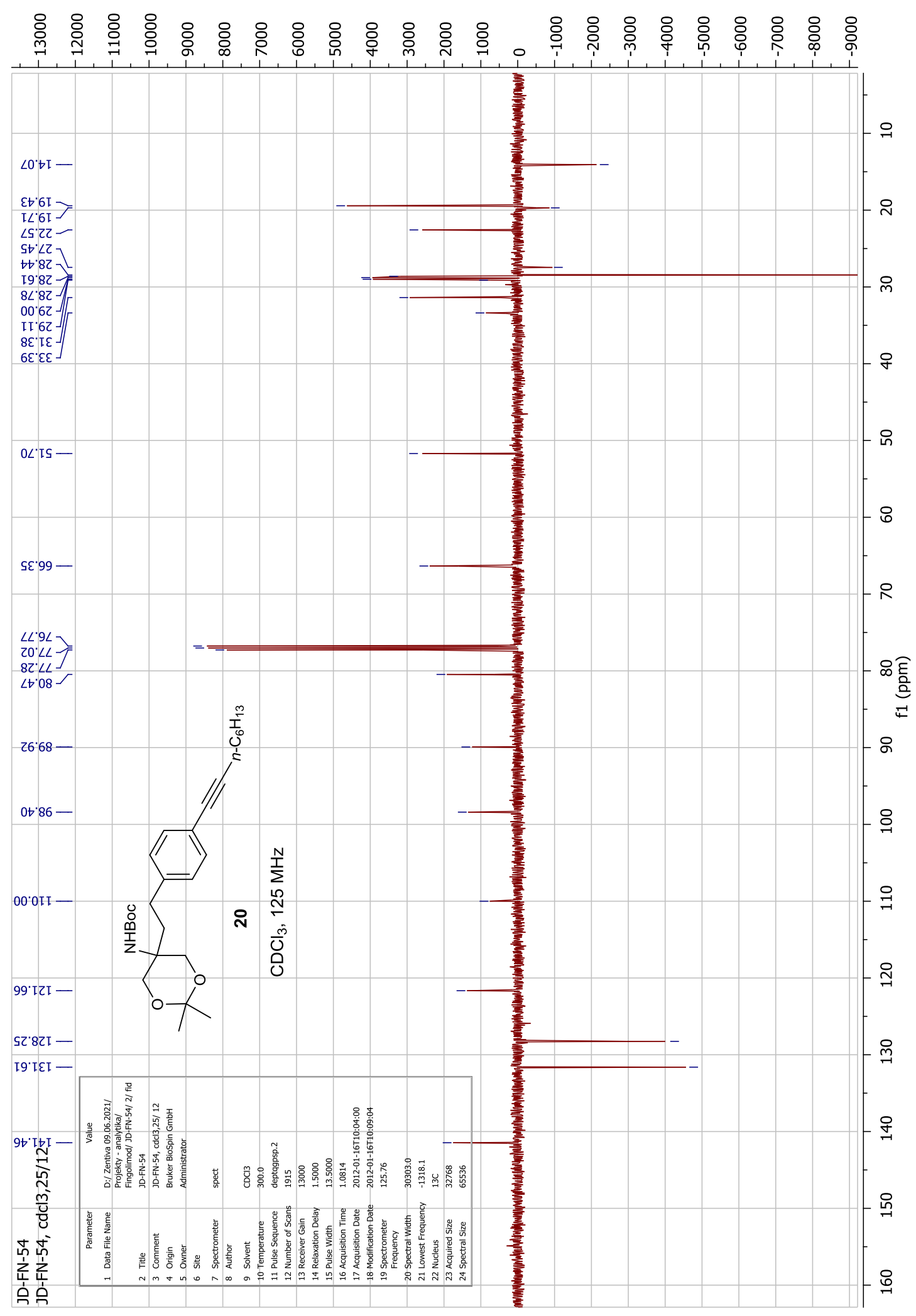




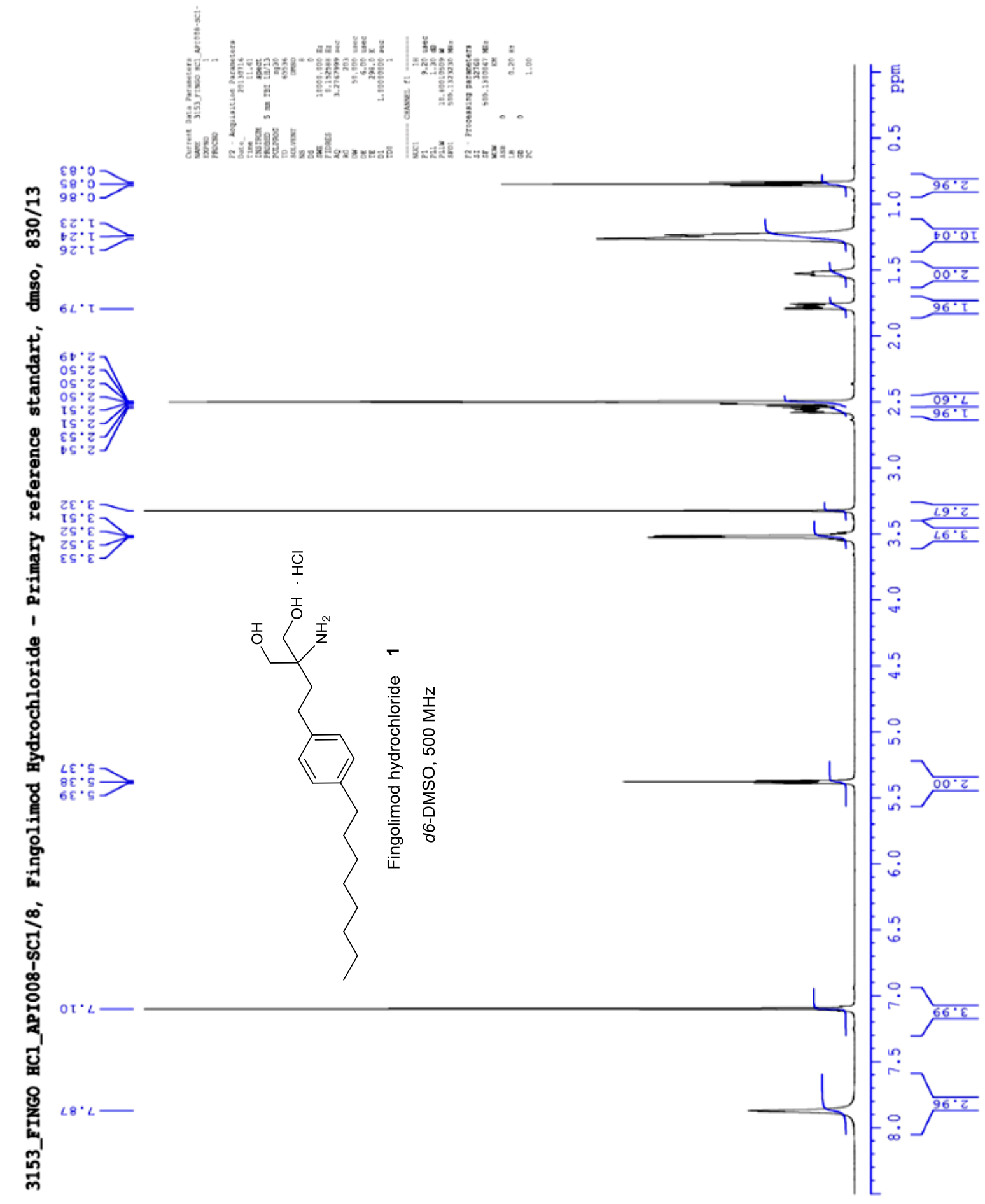




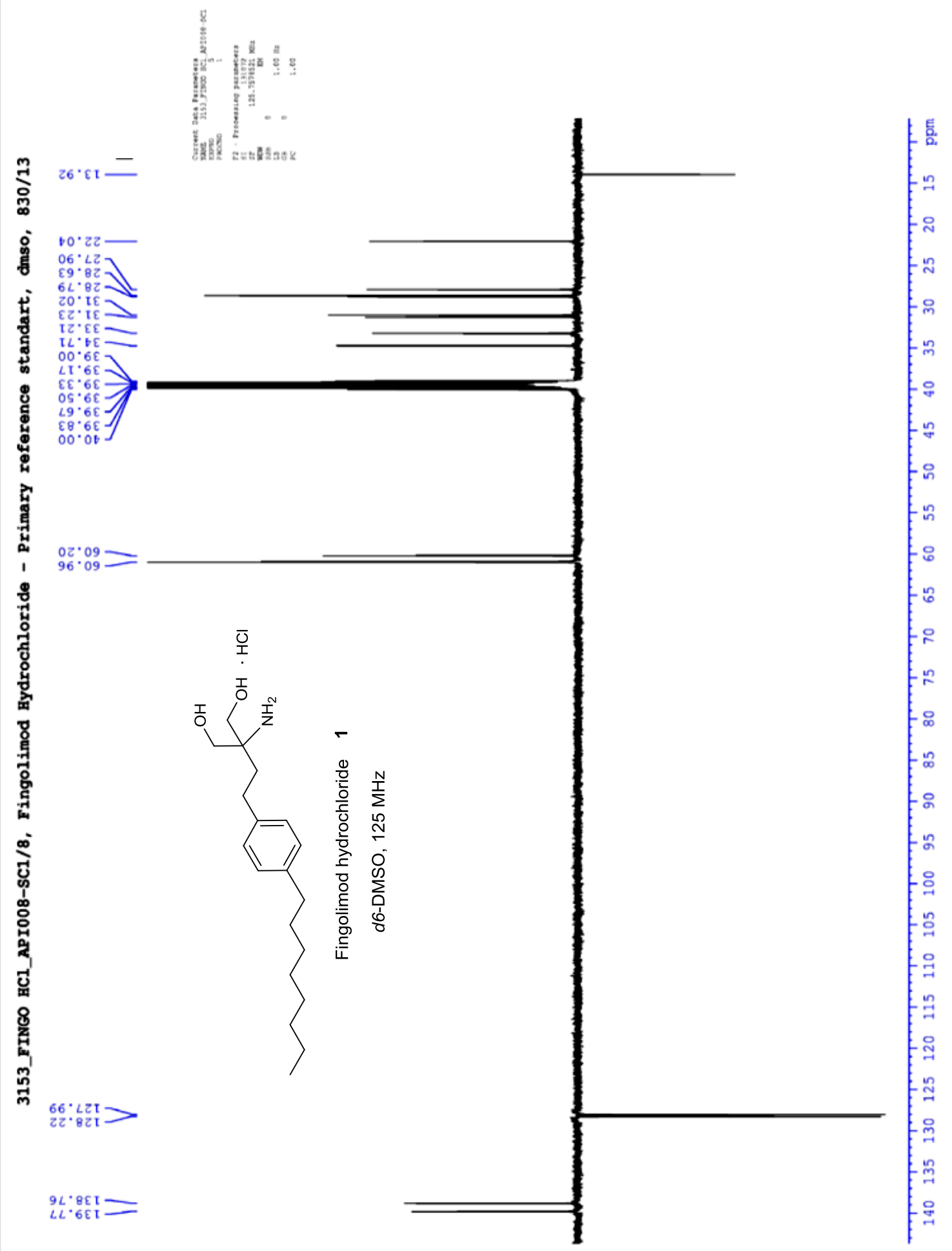




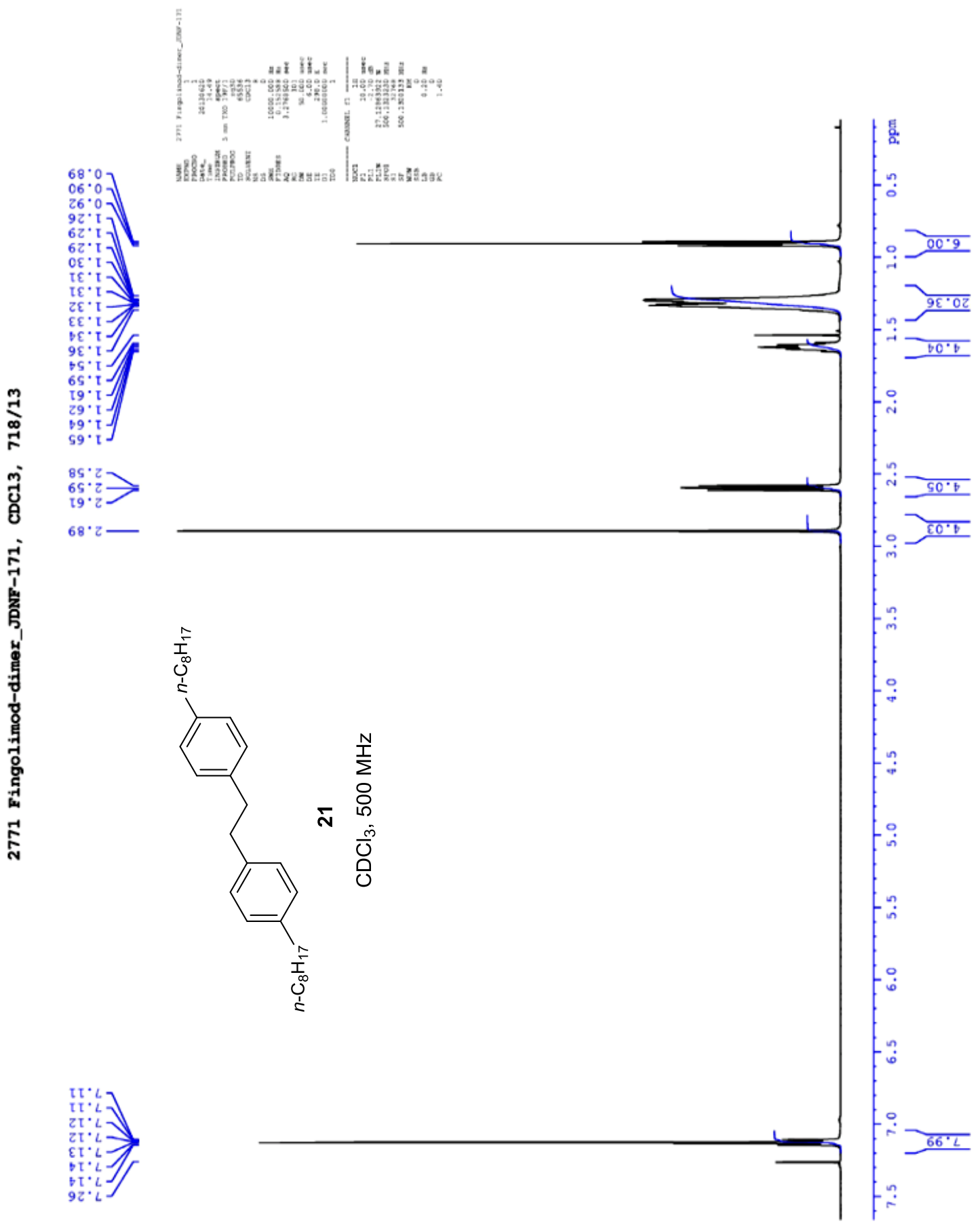




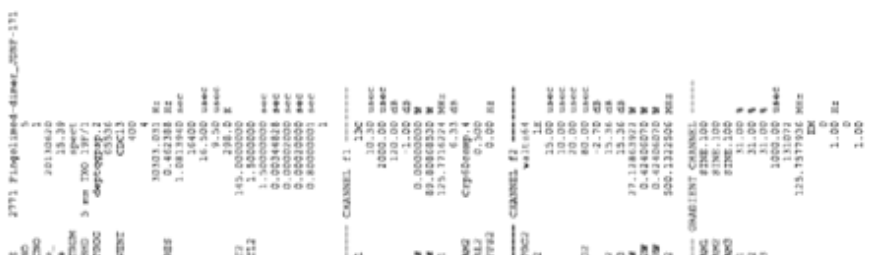

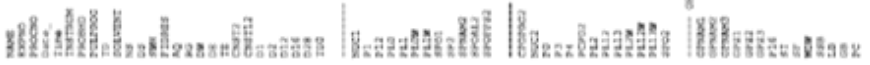

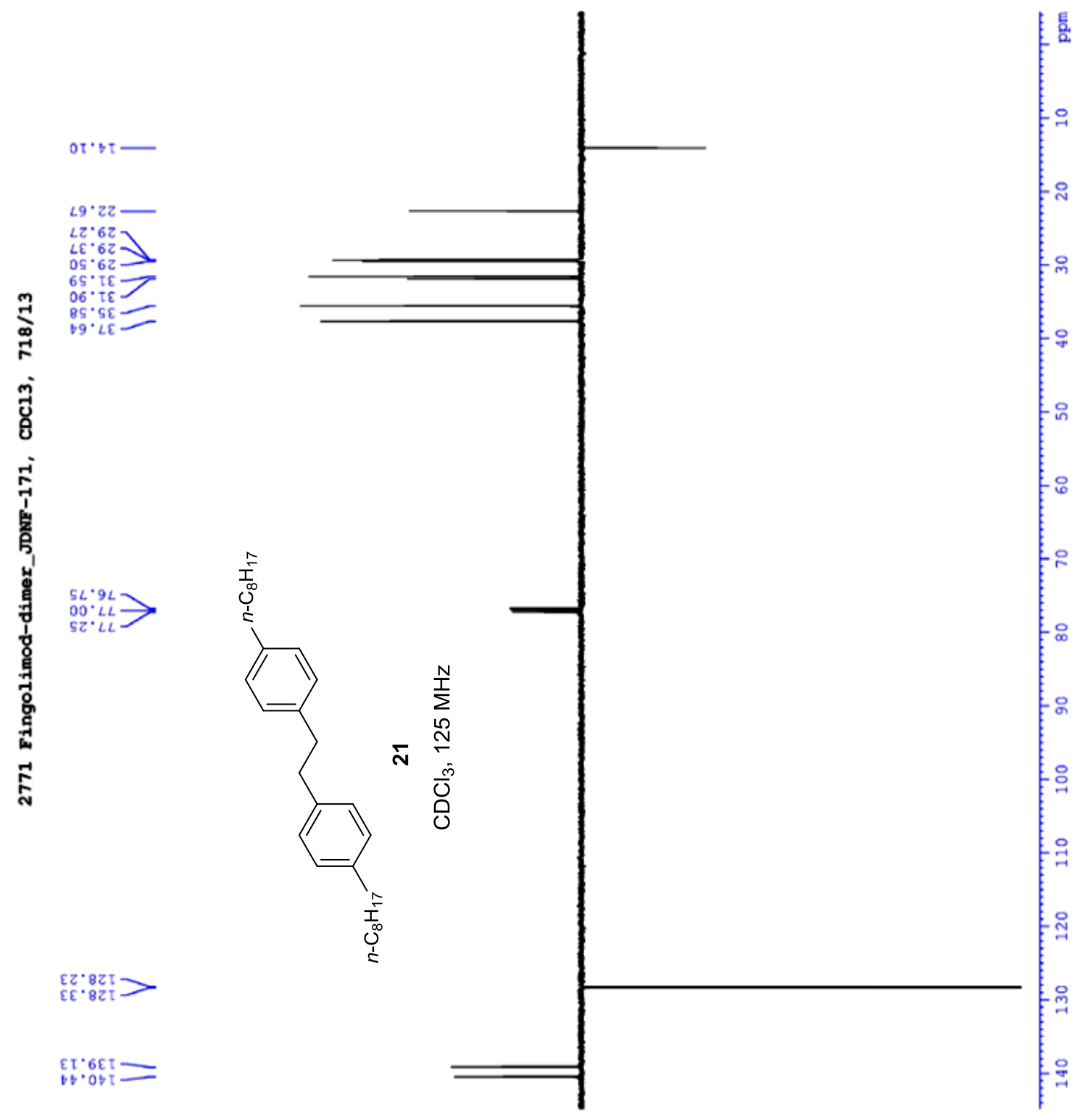




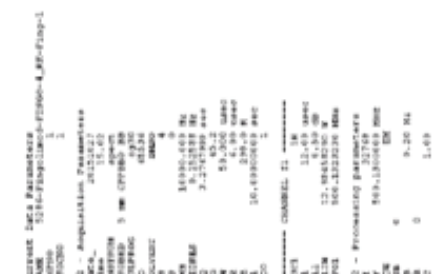

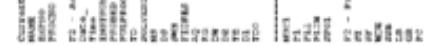

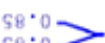

${ }_{58}^{50^{\circ}}{ }^{\circ}>$

$\varepsilon z^{*} \div$
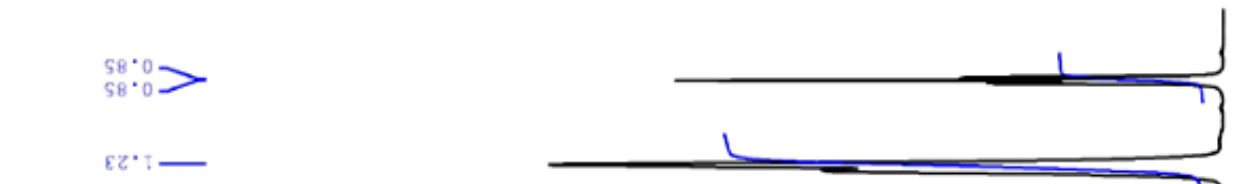

TS ${ }^{\circ} \mathrm{E}-$

โ $6^{\circ} \mathrm{E}$
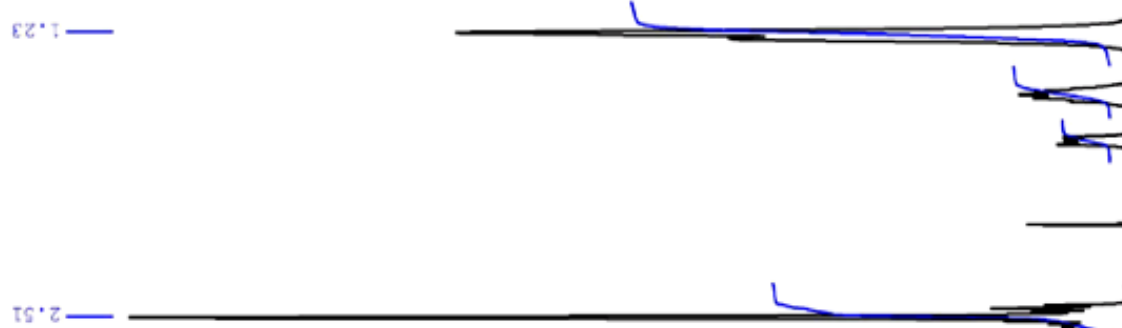

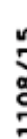
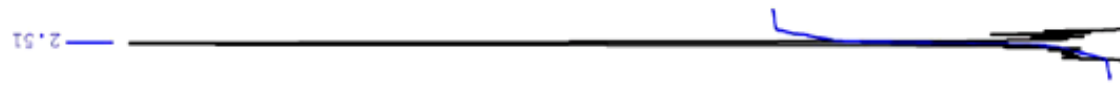



$2 t \cdot s$

.

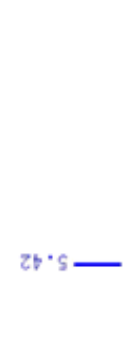

"wit-

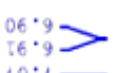

$20 \%$
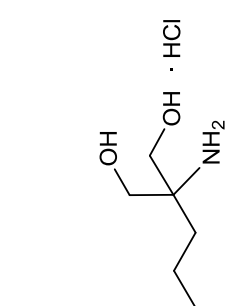

ত্ড

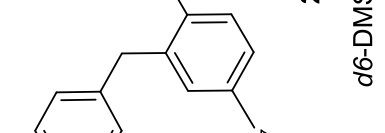

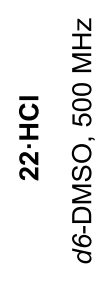

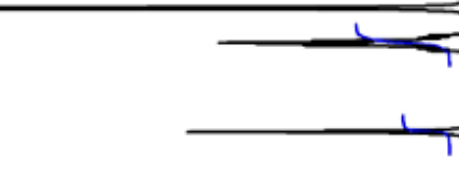

?दि

$\longdiv { 9 5 + 1 }$

$\because$

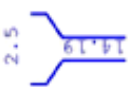

$\stackrel{\circ}{\circ}$

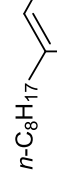
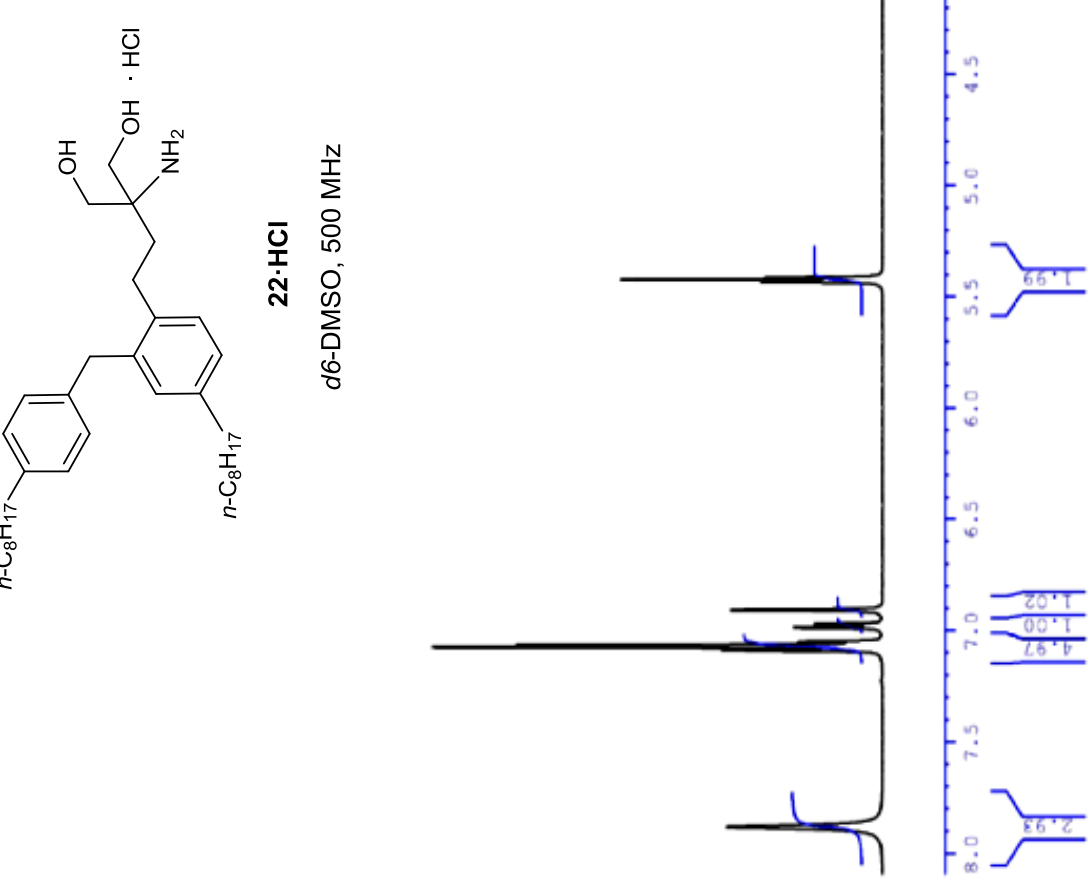

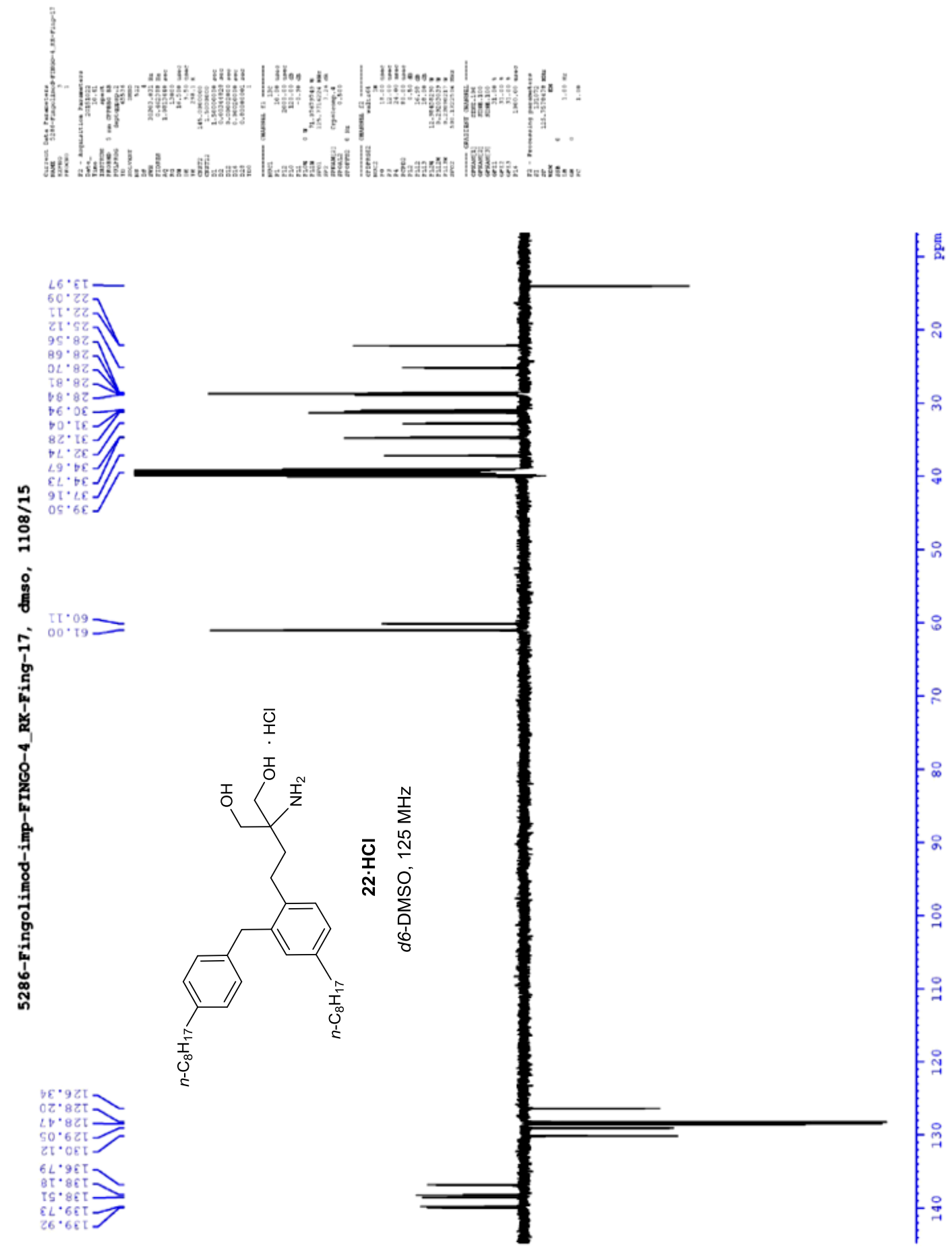


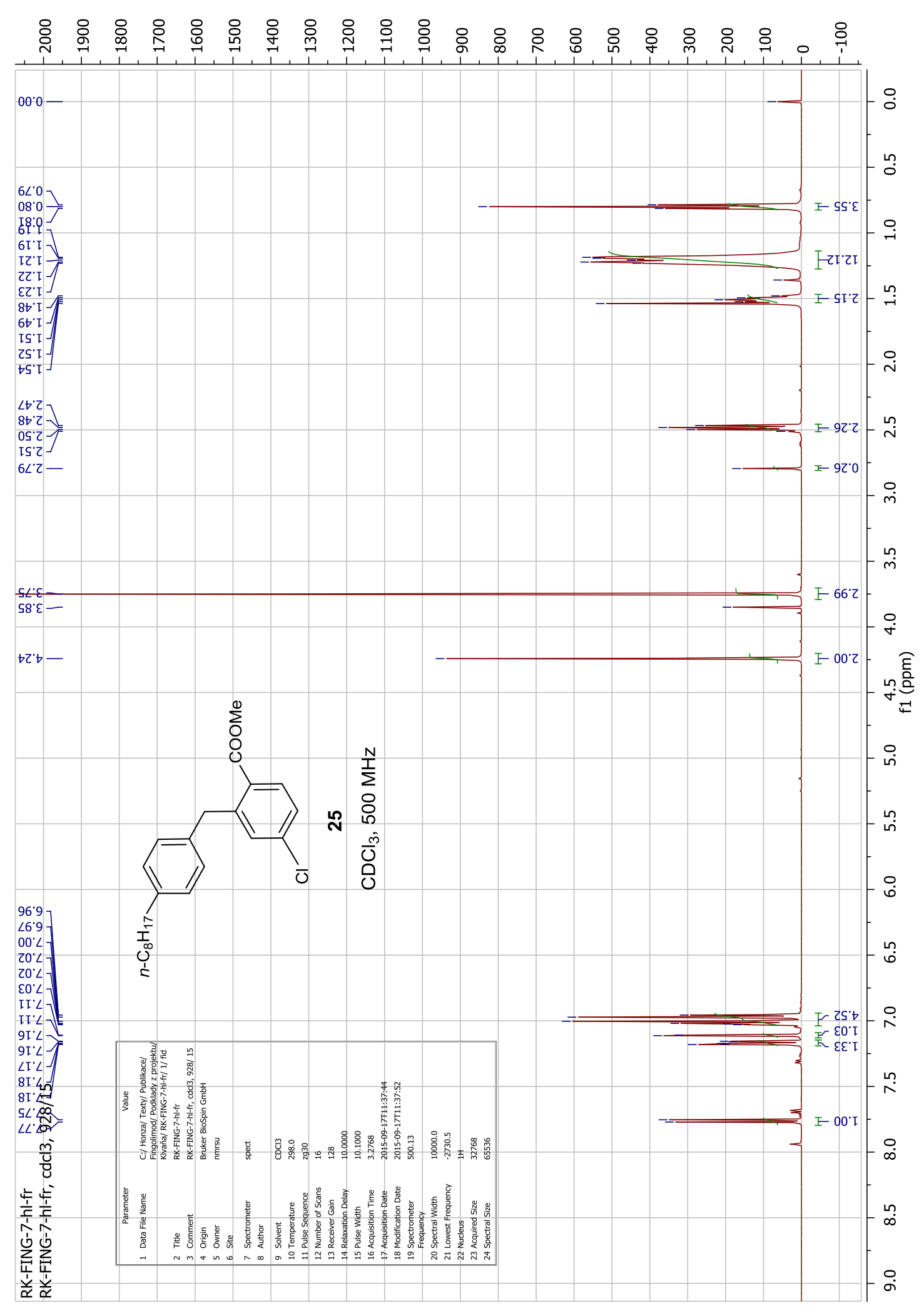




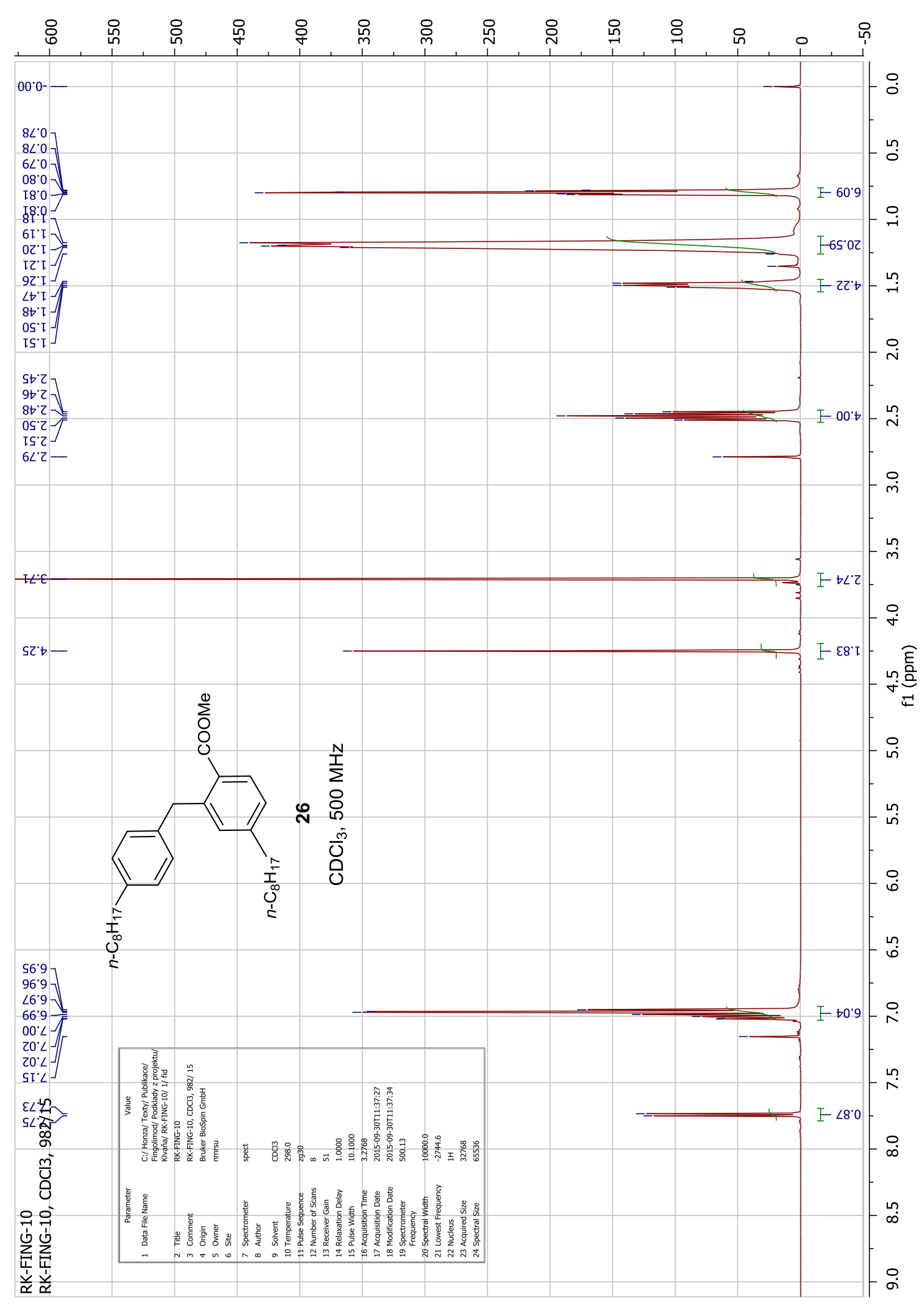




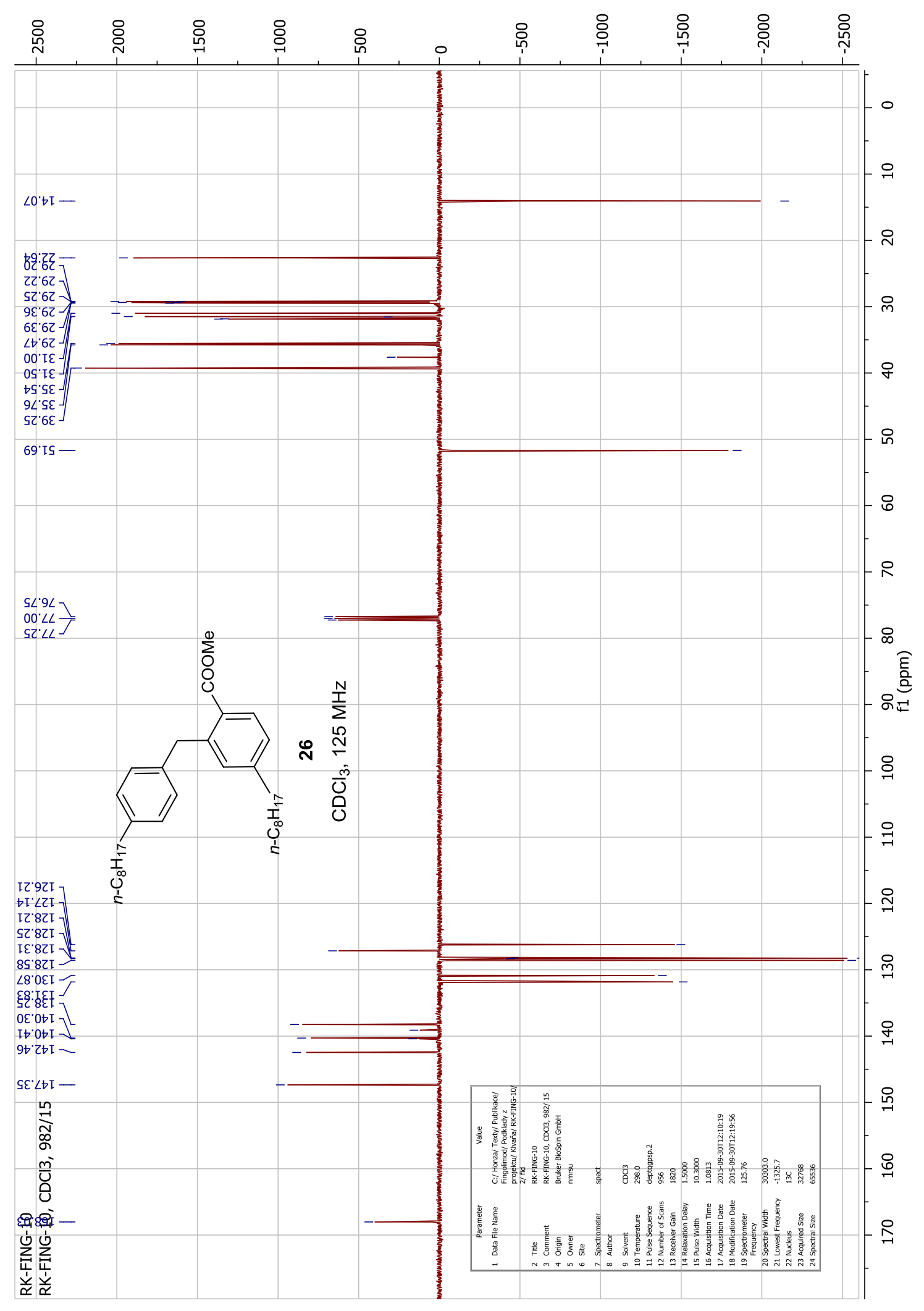




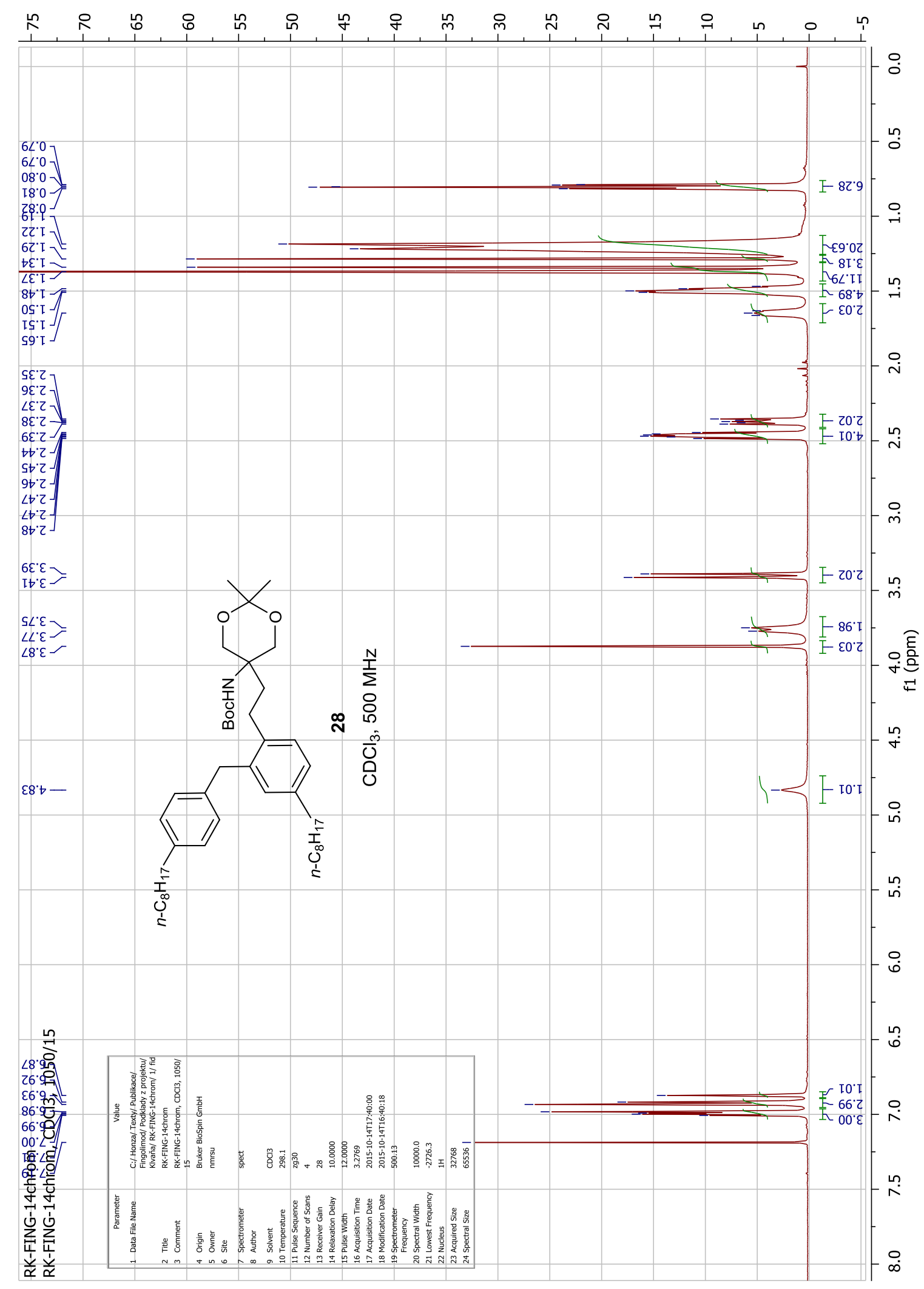




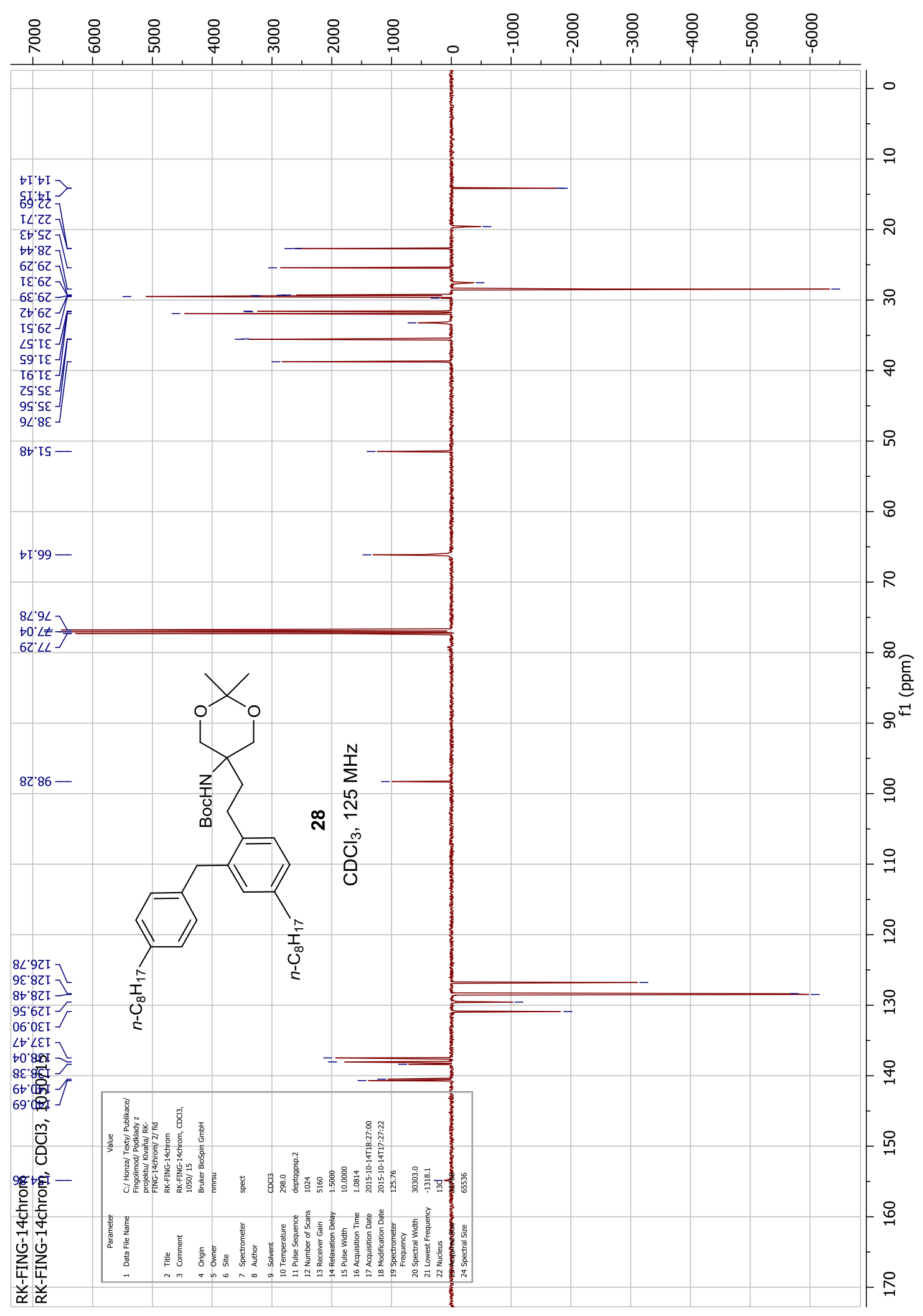

